\title{
Satellite observations of cirrus clouds in the Northern Hemisphere lowermost stratosphere
}

\author{
R. Spang ${ }^{1}$, G. Günther ${ }^{1}$, M. Riese ${ }^{1}$, L. Hoffmann ${ }^{2}$, R. Müller ${ }^{1}$, and S. Griessbach ${ }^{2}$ \\ ${ }^{1}$ Forschungszentrum Jülich, Institut für Energie and Klimaforschung, IEK-7, Jülich, Germany \\ ${ }^{2}$ Forschungszentrum Jülich, Jülich Supercomputing Centre, JSC, Jülich, Germany \\ Correspondence to: R. Spang (r.spang@fz-juelich.de)
}

Received: 24 March 2014 - Published in Atmos. Chem. Phys. Discuss.: 14 May 2014

Revised: 25 November 2014 - Accepted: 7 December 2014 - Published: 27 January 2015

\begin{abstract}
Here we present observations of the Cryogenic Infrared Spectrometers and Telescopes for the Atmosphere (CRISTA) of cirrus cloud and water vapour in August 1997 in the upper troposphere and lower stratosphere (UTLS). The observations indicate a considerable flux of moisture from the upper tropical troposphere into the extratropical lowermost stratosphere (LMS), resulting in the occurrence of highaltitude optically thin cirrus clouds in the LMS.

The locations of the LMS cloud events observed by CRISTA are consistent with the tropopause height determined from coinciding radiosonde data. For a hemispheric analysis in tropopause relative coordinates an improved tropopause determination has been applied to the European Centre for Medium-Range Weather Forecasts (ECMWF) temperature profiles. We found that a significant fraction of the cloud occurrences in the tropopause region are located in the LMS, even if a conservative overestimate of the cloud top height (CTH) determination by CRISTA of $500 \mathrm{~m}$ is assumed. The results show rather high occurrence frequencies $(\sim 5 \%)$ up to high northern latitudes $\left(70^{\circ} \mathrm{N}\right)$ and altitudes well above the tropopause (>500 $\mathrm{m}$ at $\sim 350 \mathrm{~K}$ and above) in large areas at mid- and high latitudes.

Comparisons with model runs of the Chemical Lagrangian Model of the Stratosphere (CLaMS) over the CRISTA period show a reasonable consistency in the retrieved cloud pattern. For this purpose a limb ray tracing approach was applied through the 3-D model fields to obtain integrated measurement information through the atmosphere along the limb path of the instrument. The simplified cirrus scheme implemented in CLaMS seems to cause a systematic underestimation in the CTH occurrence frequencies in the LMS with respect to the observations. The observations together with
\end{abstract}

the model results demonstrate the importance of isentropic, quasi-horizontal transport of water vapour from the subtropics and the potential for the occurrence of cirrus clouds in the lowermost stratosphere and tropopause region.

\section{Introduction}

A large proportion of the uncertainties of climate change projections by general circulation models (GCMs) arises from poorly understood and represented interactions and feedbacks between dynamic, microphysical, and radiative processes affecting cirrus clouds (IPCC, 2014). Modelled climates are sensitive even to small changes in cirrus coverage or ice microphysics (Kärcher and Spichtinger, 2010). Fusina et al. (2007) point out that the net radiative impact strongly depends on ice water content, crystal number concentration, and size distribution. Small changes in the effective radius of the size distributions can substantially modify the surface temperatures.

Recent GCM studies (Sanderson et al., 2008; Mitchell et al., 2008) indicate that the climate impact of cirrus clouds depends in particular on the fall speed of ice particles, which in turn depends on ice nucleation rates (i.e. the concentrations of small ice crystals). The overall net warming effect of cirrus clouds can be substantially reduced by changing the concentrations of small ice crystals (i.e. the degree of bimodality) of the particle size distribution (PSD). The size distribution strongly affects the representative PSD ice fall speed. Mitchell and Finnegan (2009) investigated this sensitivity in more detail and concluded that cirrus clouds are a logical candidate for climate modification efforts. 
The large uncertainties in climate prediction caused by processes involving cirrus clouds highlight the importance of more quantitative information on cirrus clouds by observations, especially for optically thin and small-particle cirrus clouds like contrails close to the tropopause, which may have an overall cooling effect in contrast to lower cirrus (Zhang et al., 2005). However, uncertainties for the climate feedback of cirrus clouds are still very large and a substantial reduction is needed (IPCC, 2014).

In particular, the altitude region of the upper troposphere and lower stratosphere (UTLS) plays an important role. Changes and variability of UTLS composition are major drivers of surface climate change. Even small changes of spatially highly variable concentrations of water vapour $\left(\mathrm{H}_{2} \mathrm{O}\right)$ have significant effects on the atmospheric radiation balance (e.g. Solomon et al., 2010; Riese et al., 2012).

A detailed understanding and modelling of the transport pathways of water vapour, and consequently the realistic representation of total water (gaseous and condensed form), in the UTLS region are therefore crucial for the correct representation of clouds and water vapour in climate models. Comprehensive analyses of transport processes from the troposphere into the stratosphere and tracer proportions of the extratropical UTLS region have been published (e.g. Hegglin et al., 2009; Hoor et al., 2010; Ploeger et al., 2013). Rossby wave breaking (Ploeger et al., 2013) and midlatitude overshoot convection (Dessler, 2009) result in the transport and mixing of air masses into the extratropical UTLS on short timescales (weeks). On seasonal timescales, downwelling by the deep Brewer-Dobson circulation branch moistens the extratropical UTLS at altitudes above $450 \mathrm{~K}$ (Ploeger et al., 2013). Aged air masses transported into the extratropical lower stratosphere from above are moistened by methane oxidation in the upper and middle stratosphere and represent an important source of water vapour in the middle stratosphere (e.g. Jones and Pyle, 1984; Rohs et al., 2006).

The imprint of various water vapour transport ways into the lowermost stratosphere on cirrus formation has been investigated in a limited number of studies (Dessler, 2009; Montaux et al., 2010, Pan and Munchak, 2011; Wang and Dessler, 2012). The formation of cirrus clouds above the midlatitude tropopause is, so far, discussed quite controversially. Dessler (2009) found relatively high occurrence rates of cirrus above the mid- and high-latitude tropopause in spaceborne lidar data of the Cloud and Aerosol Lidar (CALIOP) instrument on the Cloud Aerosol Lidar Infrared Pathfinder Satellite Observations (CALIPSO) (Winker et al., 2010). The analysis of Dessler (2009) shows cloud top height occurrences above the tropopause of up to $30-40 \%$ for midhigh and tropical latitudes and still $0.1 \%$ at $3 \mathrm{~km}$ or 40 $50 \mathrm{~K}$ potential temperature above the tropopause. Pan and Munchak (2011) (in the following abbreviated as PM2011) showed that accurate tropopause definition and tropopause relative coordinates are important for this type of analysis and reach significantly different conclusions based on the same set of measurements. They find substantially fewer clouds above the tropopause than Dessler (2009) and in their analysis the CALIOP data do not provide sufficient evidence of a significant presence of cirrus clouds above the midlatitude tropopause. The remaining but evidential events in the tropics show occurrences of up to $24 \%$ in the western Pacific and are usually located between the cold point and the lapse rate tropopause (up to $2.5 \mathrm{~km}$ above). PM2011 speculated that most of these clouds are triggered by gravitywave-induced temperature disturbances, which typically are observed above deep convection areas (e.g. Hoffmann and Alexander, 2010).

In contrast, cloud observations by midlatitude lidar stations show frequent events at and above the tropopause (e.g. Keckhut et al., 2005; Rolf, 2013). Many of them coincide with the observations of a secondary tropopause (Noël and Haeffelin, 2007). Isentropic transport into and mixing of subtropical air masses with tropospheric high water values in the midlatitude and polar LMS (lowermost stratosphere) may cause such events, and Montaux et al. (2010), in a case study, were able to reproduce the observation of such a cloud with an isentropic transport model by implementing a simple microphysical cloud model. However, in this study, the cloud was observed just at the tropopause and not significantly above. Eixmann et al. (2010) investigated the dynamical link between poleward Rossby wave breaking (RWB) events and the occurrence of upper tropospheric cirrus clouds for lidar measurements above Kühlungsborn $\left(54.1^{\circ} \mathrm{N}, 11.8^{\circ} \mathrm{E}\right)$. For three similar cirrus events, they found a strong link between low values of potential vorticity (a proxy for RWB activity), enhanced updraught velocities, and cloud ice water content. They concluded that, based on the climatology of poleward RWB events following the method of Gabriel and Peters (2008), a parameterisation of the formation or occurrence of high and thin cirrus clouds seems to be possible.

Although there are a couple of ground-based lidar observations suggesting the presence of cirrus clouds in the lowermost stratosphere (LMS), a region strongly influenced by isentropic (quasi-horizontal) transport of air masses from the tropics (Gettelman et al., 2011), there are open questions: which microphysical process and specific meteorological conditions foster the formation of ice particles in this specific region, how frequently do these cirrus clouds occur on global scales, and are clouds tops or even complete clouds significantly above the tropopause?

The currently most sensitive sensor in space for cirrus cloud observations is the CALIOP lidar. Nonetheless, Davis et al. (2010) pointed out that the space lidar on CALIPSO might miss $2 / 3$ of thin cirrus clouds with vertical optical depth $\tau<0.01$ in its current data products. Clouds with such very low optical thicknesses have been observed by airborne lidars and in situ instruments in the validation campaigns for CALIPSO. The cloud layers frequently showed ice water content (IWC) smaller than $10^{-5} \mathrm{~g} \mathrm{~m}^{-3}$ (Davis et al., 2010) These values are significantly below the current IWC 
detection limit in the CALIOP operational products of 1$4 \times 10^{-3} \mathrm{~g} \mathrm{~m}^{-3}$ (Avery et al., 2012).

Here we argue that infrared (IR) limb sounding from space provides an alternative measurement technique of high sensitivity for the detection of optically thin clouds (Mergenthaler et al., 1999; Spang et al., 2002; Massie et al., 2007; Griessbach et al., 2014), subvisible cirrus (SVC) defined by the extinction range $2 \times 10^{-4}-2 \times 10^{-2} \mathrm{~km}^{-1}$ (Sassen et al., 1989), or the even thinner ultra-thin tropical cirrus (UTTC) (Peter et al., 2003; Luo et al., 2003). The IR limb sounder detection sensitivity for clouds is in the range of spaceborne lidar measurements (Höpfner et al., 2009; Spang et al., 2012). A $100 \mathrm{~km}$ or even $1 \mathrm{~km}$ horizontally extended cirrus cloud is detectable by an IR limb sounder with an ice water content (IWC) of $3 \times 10^{-6}$ and $3 \times 10^{-4} \mathrm{~g} \mathrm{~m}^{-3}$ respectively (Spang et al., 2012), assuming that the cloud fills the vertical field of view of the instrument completely. These values represent even better detection sensitivity than the current CALIOP cloud products.

In this paper we present new analyses of measurements from the Cryogenic Infrared Spectrometers and Telescopes for the Atmosphere (CRISTA) instrument during its second Space Shuttle mission in August 1997 (CRISTA-2) (Grossmann et al., 2002). Due to its unique combination of moderate spectral resolution, high horizontal along-track and crosstrack sampling, and good vertical resolution and sampling, the CRISTA measurements are a unique data set for IR limb sounders in spite of information available from more modern satellite missions today. A reanalysis of the data set can add complementary information, especially for optically thin clouds compared to nadir passive and active instruments as well as limb sounders in the UV-vis and microwave wavelength region. The characterisation of frequent observations of Northern Hemisphere mid- and high-latitude cirrus clouds in respect to the tropopause (above or below) are the focus of the present study.

The paper is organised as follows. First we introduce the CRISTA instrument and the data analysis methods applied, followed by a section presenting the cloud top occurrence frequencies (COF) in respect to the tropopause. The comparison of CRISTA water vapour and cloud measurements presented in Sect. 4 suggests a strong influence of horizontal transport processes of high water vapour values from the subtropics to the latitude of cloud formation. A comparison with a global transport model can help to understand the origin and evolution with time of the cloud observations around the tropopause. This is investigated in Sect. 5 with a Lagrangian transport model containing a simple cirrus parameterisation.

\section{Observations and analysis methods}

\subsection{CRISTA satellite instrument}

The CRISTA instrument measured roughly 1 week in the UTLS during two space shuttle missions in November 1994 and August 1997 (Offermann et al., 1999, Grossmann et al., 2002). The measurements demonstrate the potential of the IR limb viewing technique to provide information on several trace gas constituents (Riese et al., 1999a, 2002) and clouds (Spang et al., 2002) with high spatial resolution. The spectral information in the wavelength $(\lambda)$ region $4-15 \mu \mathrm{m}$ is scanned with a resolution of $\lambda / \Delta \lambda=\sim 500$, which is equivalent to $1.6 \mathrm{~cm}^{-1}$ at $830 \mathrm{~cm}^{-1}$. The vertical field of view (resolution) is of the order of $1.5 \mathrm{~km}$, and a typical vertical sampling of $2 \mathrm{~km}$ was used during CRISTA-2. A horizontal along-track sampling of 200 to $400 \mathrm{~km}$ was applied, depending on the measurement mode. An across-track sampling of $\sim 600 \mathrm{~km}$ was achieved by using three telescopes for three viewing directions simultaneously. A typical measurement net in the Northern Hemisphere is illustrated in Fig. 1. Due to the overlapping orbits and the $57^{\circ}$ orbit inclination, an even higher horizontal cross-track sampling becomes obvious at high northern latitudes ( $\sim 200 \mathrm{~km}$ for north of $60^{\circ}$ latitude). The spectrometers and optics were cryogenically cooled by helium to allow for measurements in the middle and far infrared $(4-70 \mu \mathrm{m})$.

The instrument was hosted by the free-flyer system ASTRO-SPAS (Wattenbach and Moritz, 1997). The accuracy of the attitude system of the platform, which was also used for two astronomic missions, is excellent. The final pointing accuracy in the limb direction for the three viewing directions is of the order of $300 \mathrm{~m}$ (Riese et al., 1999a; Grossmann et al., 2002). The effect of refraction through the atmosphere in the limb direction is considered in the tangent height determination and can reduce the actual tangent height by up to $\sim 300 \mathrm{~m}$ at $12 \mathrm{~km}$ altitude. This correction is crucial for the cloud top height determination in the next section.

Here, we focus on the CRISTA-2 mission, which took place from 8 to 15 August 1997. Details on the instrument, the mission, and the specific water vapour retrieval are given in Grossmann et al. (2002), Offermann et al. (2002), and Schaeler et al. (2005) respectively. For the water vapour retrieval, the continuous spectral scans of the spectrometers allow the selection of a spectral water vapour feature most suitable at tropopause altitudes (at a wavelength of $12.7 \mu \mathrm{m}$ ). An onion peeling retrieval is applied to the CRISTA measurements (Riese et al., 1999; Schaeler and Riese, 2001) and has the advantage of no upward propagation of errors to altitude levels above the optically thick cloud, even if the spectrum is not removed from the retrieval. The contamination by the strong cloud emissions and scattering processes in the corresponding IR spectra are too complex to model accurately in the retrieval process, and these measurements are not taken into account in the water vapour distributions presented later. 


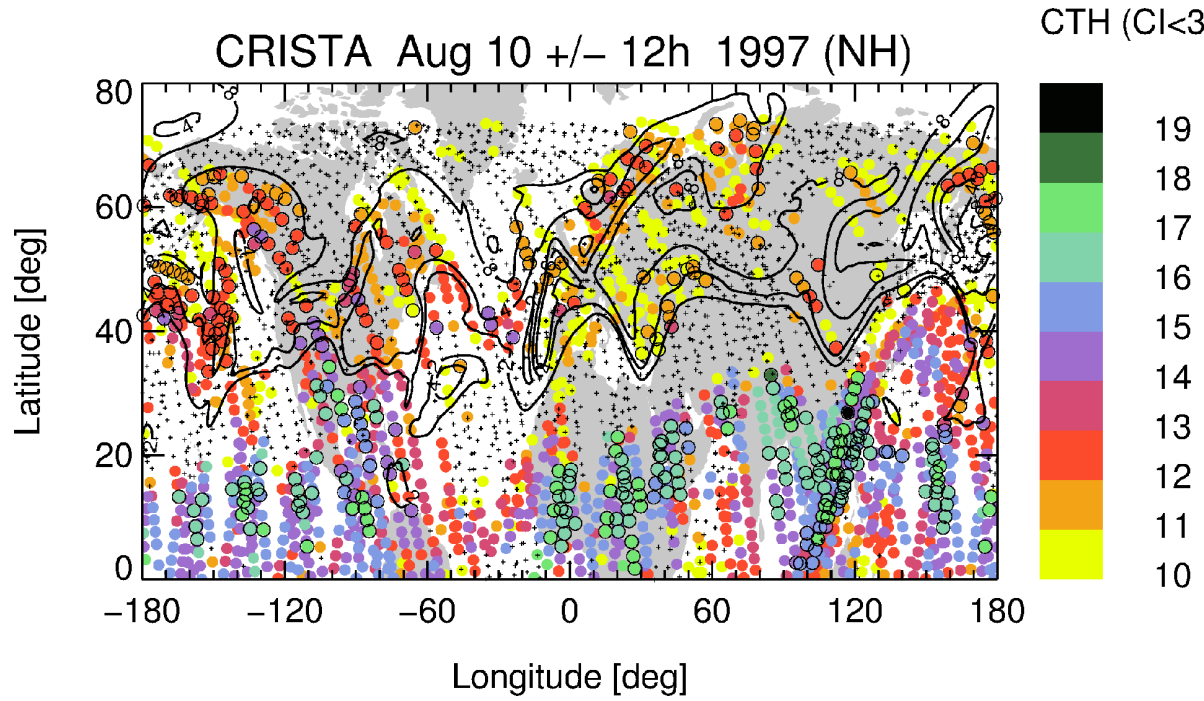

Figure 1. CRISTA cloud top height distribution for 10 August 1997 at 10 00:00 UTC $\pm 12 \mathrm{~h}$ (coloured circles). Profiles with no cloud indications are marked by black crosses. Overlaid in black are contours of potential vorticity at 2, 4, and 8 PVU at the $350 \mathrm{~K}$ isentrope. Cloud tops with PV values greater than the proxy threshold 2 PVU for the dynamical tropopause are highlighted by black borders around the coloured circles for CTH (cloud top height).

The absolute accuracy of the water vapour retrieval is estimated to be $22 \%$ (Offermann et al., 2002), though it is better at specific altitudes $(10 \%$ at $215 \mathrm{hPa})$. The precision is estimated to be $8-15 \%$ (Schaeler et al., 2005).

\subsection{CRISTA Cloud detection}

In the following, special emphasis is put on cloud top height (CTH) observations at northern hemisphere midlatitudes in respect to the tropopause, where isentropic horizontal transport of water vapour from the subtropics to high latitudes may trigger cirrus formation in the LMS. The cloud detection for IR limb sounders has been investigated in detail over the last decade (Spang et al., 2012, and references therein). For spectrally resolved measurements, simple colour-ratiobased methods are shown to be robust and accurate for the detection of cloudy spectra (e.g. Spang et al., 2001; Sembhi et al., 2012). For the following analyses, the cloud index (CI) is defined by the colour ratio of the mean radiances from 788 to $796 \mathrm{~cm}^{-1}$ divided by the mean radiances from 832 to $834 \mathrm{~cm}^{-1}$, a method which has already been applied to various airborne and spaceborne limb IR instruments (e.g. Spang et al., 2002, 2004, 2007). The corresponding CTH is the first tangent height where CI falls below the defined threshold value $\left(\mathrm{CI}_{\text {thres }}\right)$. The left panel of Fig. 2 illustrates a CI profile with the transition from clear-sky conditions $(8>\mathrm{CI}>4.5)$ to cloudy conditions ( $\sim 4>\mathrm{CI}>1.1)$, where optically thick conditions are in line with a $\mathrm{CI}$ value of $\sim 1.2$.

Various studies have shown that the detection sensitivity is linked to the detection threshold and depends to some extent on the seasonal variation in the trace gas concentrations in the applied spectral windows (e.g. Spang et al.,
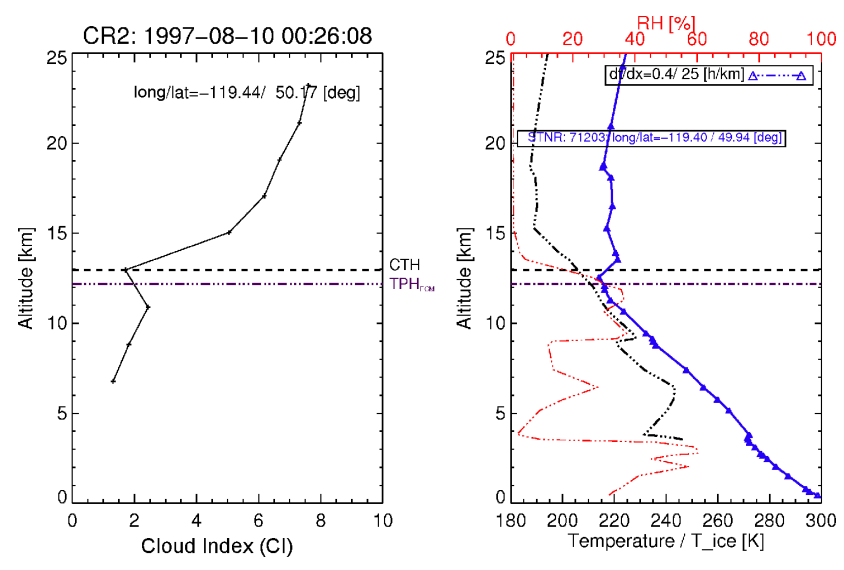

Figure 2. Cloud index (CI) profile during CRISTA-2 (left) and coincident radiosonde measurements (right) at midlatitudes. The profiles on the right side show temperature (blue) and relative humidity (red). The ice saturation temperature curve is superimposed as the black dash-dotted curve. Horizontal lines indicate cloud top height (CTH) from the CRISTA measurements (dashed) and the so-called "high-resolution" tropopause height $\left(\mathrm{TPH}_{\mathrm{hr}}\right)$ from ERA Interim temperature data (dash-dotted); for details see Sect. 2.5.

2012). The main limiting effect of the cloud index method are high water vapour continuum emissions (for mixing ratios $>500 \mathrm{ppmv}$ ) in the mid-troposphere and below. Under such conditions a definite discrimination between clouds and high water vapour becomes difficult (Spang et al., 2004, 2007). Radiative transport models calculations show that water vapour variations in the tropical tropopause region have only a marginal effect on the numerator in the CI colour ratio 
and the corresponding CI threshold approach (even a factorof- 2 reduction in water vapour, like that observed at the tropical hygropause compared to the higher stratospheric value, only causes a $\Delta \mathrm{CI}_{\max }=0.02$ ). The water vapour line emissions are too weak to compete with dominating $\mathrm{CO}_{2}$ and $\mathrm{O}_{3}$ emissions in the $788-796 \mathrm{~cm}^{-1}$ region.

Spang et al. (2012) showed that limb IR measurements of cirrus clouds are most sensitive to the integrated surface area density along the limb path (area density path, ADP) and that ADP is a useful quantity for comparisons with global models or measurements in combination with radiative-transport models. For example, the limb path can be traced through the 3-D model output to generate the ADP quantity. ADP and CI show an excellent correlation, and ADP can be retrieved from the measured CI values (Spang et al., 2012). For a homogeneous limb path segment, ADP and limb ice water path (IWP) are related by the simple equation

$\mathrm{ADP}=3 \cdot \operatorname{IWP} /\left(R_{\text {eff }} \cdot \rho_{\text {ice }}\right)$,

where $\rho_{\text {ice }}$ is the mass density of ice and $R_{\text {eff }}$ is the effective radius of the particle size distribution. More generally, the limb IWP can be computed by the following relations, depending on which parameters are known from the model or measurements:

$\operatorname{IWP}=\int_{0}^{\infty} \operatorname{IWCd} x=\int_{0}^{\infty} V \cdot \rho_{\text {ice }} \mathrm{d} x=\frac{1}{3} \int_{0}^{\infty} A \cdot R_{\text {eff }} \cdot \rho_{\text {ice }} \mathrm{d} x$,

where $R_{\text {eff }}$ and IWC are defined by the model and $V$ and $A$ represent volume and surface area density respectively (Spang et al., 2012). The authors retrieved a detection sensitivity in ADP for the cloud index approach of the order of $\mathrm{ADP}_{\text {thres }}=10^{7} \mu \mathrm{m}^{2} \mathrm{~cm}^{-2}$. If one assumes a typical effective radius for optically thin cirrus clouds of $10 \mu \mathrm{m}$, this results in an equivalent limb IWP of $0.3 \mathrm{gm}^{-2}$.

Emissions by aerosol particles in the UTLS region can affect the CI values in a similar way to clouds, and a differentiation between ice and aerosol particles would be useful. Due to the very low volcanic activity after the major eruption of Pinatubo in 1991 for the rest of the 90s, the year of the CRISTA mission 1997 and the following years are a period of exceptionally low UTLS aerosol load in the tropics (e.g. Vernier et al., 2011) and at midlatitudes (SPARC, 2006). The long-term records of measured aerosol extinctions by the satellite instruments SAGE II (at 0.5 and $1 \mu \mathrm{m}$ ) and HALOE (at $5 \mu \mathrm{m}$ ) for 1997 show extremely low values for this period (SPARC, 2006). Radiative-transfer model (RTM) calculations with extinctions transferred from the HALOE wavelength to the $12 \mu \mathrm{m}$ region of CRISTA as well as for particle size distribution from balloon measurements at midlatitudes (Deshler et al., 2003) have been performed to quantify the effect on the cloud index approach. The results show the aerosol equivalent $\mathrm{CI}$ values in the range of 4 to 6 . A CI $<3$ cannot be achieved for 1997 conditions (see also Spang et al.,
2002). Consequently, we can exclude the possibility that the detected events with $\mathrm{CI}_{\text {thres }}=3$ in the following analyses are related by radiance emissions of the background aerosol or caused by an injection of volcanic aerosol into the tropics or midlatitudes.

Further, for a more direct test we have applied to the data a new method for the differentiation of sulfuric acid aerosol and ice particles developed for the MIPAS (Michelson Interferometer for Passive Atmospheric Sounding) instrument by Griessbach et al. (2013). The method uses additional wavelength regions at $\sim 960 \mathrm{~cm}^{-1}$ and $1225 \mathrm{~cm}^{-1}$ to provide an aerosol/ice classification. The different spectral slope of the continuum-like emissions, such as ice $\mathrm{H}_{2} \mathrm{SO}_{4}$, and volcanic ash, makes the differentiation of these potential aerosol and cloud types possible. If we apply the detection restriction of $\mathrm{CI}<3$, the new method shows no aerosol but usually ice signals for most of the CRISTA spectra around the tropopause. This analysis corroborates the conclusion derived above on the basis of RTM calculations that values of CI $<3$ cannot be caused by stratospheric aerosol.

Cloud top heights detected with a cloud index threshold value of $\mathrm{CI}_{\text {thres }}=3$ are presented in Fig. 1. Inhomogeneities in the measurement net are caused by special measurement modes, where the free flyer was pointed to specific regions of interest (e.g. the warm pool region over Micronesia or validation sites). The dense horizontal coverage of the measurement net over $24 \mathrm{~h}$ (here presented for 9 to 10 August 1997, noon to noon) allows us to track the horizontal transport patterns of trace gases for example streamers (e.g. Riese et al., 1999a, 2002) in conjunction with meteorological parameters such as the potential vorticity (PV). Figure 1 shows PV contours for the $350 \mathrm{~K}$ isentrope. All meteorological data used in this study are from the ERA Interim reanalysis data set provided by the European Centre for Medium-Range Weather Forecasts (ECMWF) (Dee al., 2011). The CTH distribution and PV contours suggest a link between the dynamical features of horizontal transport processes such as Rossby wave breaking events (e.g. Juckes and McIntyre, 1987) and the presence of high cirrus clouds. Contours of low PV (4 and 8 PVU, with $1 \mathrm{PVU}=10^{-6} \mathrm{~K} \mathrm{~m}^{2} \mathrm{~kg}^{-1} \mathrm{~s}^{-1}$ ) highlight elongated air masses from the subtropics to mid- and high latitudes where coincidently high-altitude clouds appear in the CRISTA observations.

High CTHs (> $12 \mathrm{~km})$ are frequently present at mid- (40$\left.60^{\circ} \mathrm{N}\right)$ and even at high geographic latitudes $\left(>60^{\circ} \mathrm{N}\right)$ in regions of low PV. Nearly all of these high CTH locations show PV values greater 2 PVU, a common threshold for the dynamical tropopause in the subtropics (Holton et al., 1995), and are marked in Fig. 2 by black circles. Whether these clouds are really formed in the LMS and not just below the tropopause is a matter of particular interest in this study. In addition, in order to explore clouds in the vicinity of the tropopause, it is important to quantify accurately the uncertainties in cloud top and tropopause height. The following 
sections will present more details on the analysis method and error estimates of both parameters.

\subsection{Uncertainties in cloud top height determination}

The retrieved CTH from the CRISTA radiance profiles depends not only on the CI threshold values but also critically on the vertical sampling of the instrument (typically $2 \mathrm{~km}$ during CRISTA-2, see Fig. 2) and the vertical size of the field of view (FOV) of the instrument. The FOV of CRISTA is very well described by a Gaussian function with a full-width half maximum (FWHM) of 2.624 arcmin, which is equivalent to $\sim 1.5 \mathrm{~km}$ at $15 \mathrm{~km}$ tangent height (Offermann et al., 1999) and corresponds to a standard deviation of $\sigma_{\mathrm{FOV}}=625 \mathrm{~m}$.

Uncertainties in the $\mathrm{CTH}$ are dominated by effects of the vertical FOV. If an optically thick cloud only fills the lower part of the FOV, the attributed CTH may overestimate the real $\mathrm{CTH}$. This potential error source was investigated in detail by modelled cloud index profiles for various cloud conditions and background atmospheres (Fig. 3). We calculated the radiance profiles of the analysed wavelength regions to compare the cloud index for varying cloud altitudes $(6-20 \mathrm{~km})$ and layer thicknesses $(0.5$ and $2 \mathrm{~km})$ and extinction $\varepsilon\left(10^{+1}\right.$ to $\left.10^{-4} \mathrm{~km}^{-1}\right)$. Simulations were carried out with the line-byline radiative-transfer code RFM (Dudhia et al., 2002). Scattering processes were ignored. For a full set of simulations a realistic parameter space was chosen, i.e. CTHs between 6 and $16 \mathrm{~km}$, different reference gas atmospheres, cloud extinctions from $10^{+1}$ to $10^{-4} \mathrm{~km}^{-1}$, and box-type cloud layers with a vertical extension of $0.5,1$, and $2 \mathrm{~km}$. The calculations were performed on a $100 \mathrm{~m}$ vertical gird. The pencil beam radiance profiles were afterwards convolved with the FOV. By comparing the input $\mathrm{CTH}$ and the simulated $\mathrm{CTH}$, we estimate the maximum error in $\mathrm{CTH}$ for multiple $\mathrm{CI}$ thresholds (grey vertical lines in Fig. 3). Four different threshold values $(1.2,2,3,4)$ have been investigated for the various cloud layer extinctions and cloud vertical thickness. A detection threshold of 4 and 4.5 was applied for the MIPAS instrument (Fischer et al., 2008) in various studies for the detection of the usually optically thin polar stratospheric clouds (e.g. Spang et al., 2003; Höpfner et al., 2005). Sembhi et al. (2012) showed that $\mathrm{CI}_{\text {thres }}$ values of up to 6 are acceptable for the MIPAS measurements depending on the latitude and altitude region of interest.

Figure 3 shows the CI profiles of the pencil beam simulations and the CI profile with the FOV convolution for a homogeneous cloud layer for an optically thin $\left(\varepsilon=3 \times 10^{-3} \mathrm{~km}^{-1}\right)$ cloud between 10 to $12 \mathrm{~km}$ $(\mathrm{CTH}=12 \mathrm{~km})$ and for an optically thick $\left(\varepsilon=10^{-1} \mathrm{~km}^{-1}\right)$ cloud between 11 and $13 \mathrm{~km}(\mathrm{CTH}=13 \mathrm{~km})$. The conservative threshold $\mathrm{CI}_{\text {thres }}=1.2$ only detects optically thick clouds, and, consequently, the CTH is underestimated due to the FOV effect. Optically thinner clouds are only detectable with a less stringent threshold (CI > 1.8, Spang et al., 2005a).
The analysis for $\mathrm{CI}_{\text {thres }}=2$ shows a maximum possible $\mathrm{CTH}$ error $\left(\Delta_{\max 2}\right)$ of $0.6 \mathrm{~km}$ for all simulations. Higher thresholds result in higher detection sensitivity but cause higher uncertainties in CTH $\left(\Delta_{\max 3}=0.9 \mathrm{~km}\right.$ for $\mathrm{CI}_{\text {thres }}=3$ and $\Delta_{\max 4}=1.4 \mathrm{~km}$ for $\mathrm{CI}_{\text {thres }}=4$ ) for optically thick clouds with $\varepsilon>10^{-1} \mathrm{~km}^{-1}$. Optically thinner clouds usually cause smaller maximum CTH errors.

However, the optically thin and thick examples in Fig. 3 show that higher detection sensitivity will cause an overestimation of the CTH in the examples of 0.8 and $1.25 \mathrm{~km}$ for $\mathrm{CI}_{\text {thres }}=4$. In addition, it should be noted that the actual $\mathrm{CTH}$ error of a measurement depends not only on $\mathrm{CI}_{\text {thres }}$ but also on the relative distance of the measured tangent heights to the actual "real" cloud top (sampling). For CRISTA measurements the distances of the tangent point to the "real" $\mathrm{CTH}$ in the atmosphere are statistically almost equally distributed, with a maximum distance of $\pm 1 \mathrm{~km}$ due to the $2 \mathrm{~km}$ vertical sampling. The $\Delta_{\max }$ values above are errors of a worst-case scenario and represent the upper extreme of the FOV effect. Half of all detections of optically thick clouds will have a $\Delta_{\mathrm{CTH}}$ smaller than $\Delta_{\max } / 2$ due to the fact that the FOV error for optically thick clouds declines linearly with a declining difference between the sampled observation height and the "real" CTH (see Fig. 3).

In conclusion, the mean CTH error due to the FOV (for optically thick clouds) $\overline{\Delta_{\text {FOV }}}$ is consistent with $\Delta_{\max } / 2$. For optically thinner clouds, $\Delta_{\max }$ becomes systematically smaller (e.g. compare Fig. 3a for thin and Fig. 3b for thick conditions), and, for the more stringent $\mathrm{CI}_{\text {thres }}=2$, these clouds are only detectable at an observation height below the actual "true" CTH (negative CTH errors in Fig. 3a). In the following analyses, we used two thresholds $\left(\mathrm{CI}_{\text {thres }}=2\right.$ and $\left.\mathrm{CI}_{\text {thres }}=3\right)$ for optimisation and the best trade-off between quantified FOV effects and the best detection sensitivity for optically thin clouds. The CI values chosen are equivalent to extinction coefficients of $\varepsilon>\sim 5 \times 10^{-3} \mathrm{~km}^{-1}$ and $\varepsilon>\sim 2 \times 10^{-3} \mathrm{~km}^{-1}$ respectively and correspond to $\overline{\Delta_{\mathrm{FOV} 2}}=250 \mathrm{~m}$ and $\overline{\Delta_{\mathrm{FOV} 3}}=450 \mathrm{~m}$.

It is certainly a strong overstatement to postulate optically thick conditions for all potential cirrus cloud detections around the tropopause. How frequently cirrus clouds in the limb appear as optically thick or thin, equivalent to large and small positive biases, is unknown and therefore difficult to quantify. The slant ice water path (IWP), the IWC integrated along the line of sight (Spang et al., 2012, and also Sect. 2.2), determines the actual optical thickness of the measured spectrum in the limb direction. Radiative-transport model calculations for a characteristic diversity of cirrus size distribution parameters (Griessbach et al., 2014) under the assumption of vertically and horizontally homogeneous cloud layers show that the largest FOV-induced CTH errors $\Delta_{\max }$ (for $\varepsilon>10^{-1} \mathrm{~km}^{-1}$ ) can be generated from a cloud layer with IWC $>\sim 3$ ppmv $\left(>5 \times 10^{-4} \mathrm{~g} \mathrm{~m}^{-3}\right.$ ) (Spang et al., 2007, Fig. 5). This is a common value in IWC in situ measurements in the upper troposphere, typically close to and 

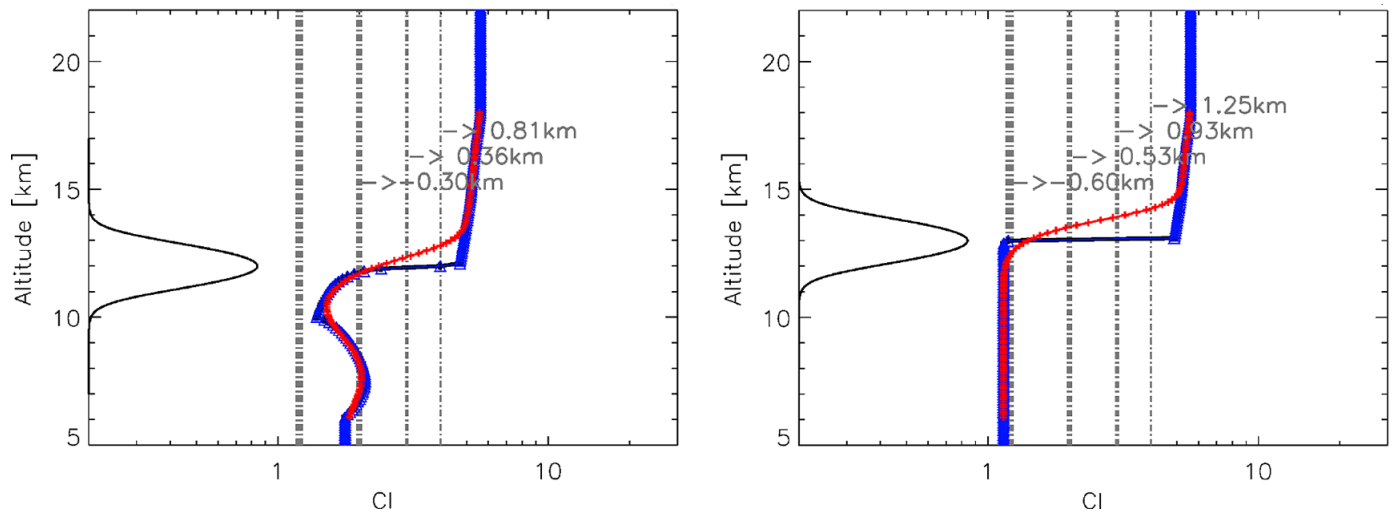

Figure 3. Examples of cloud index profile computed from modelled radiance profiles with high vertical resolution $(0.1 \mathrm{k} \cdot \mathrm{m}$, in blue) for a $2 \mathrm{~km}$ thick cloud layer with cloud top at 12 and $13 \mathrm{~km}$ for optically thin (left) and thick (right) conditions respectively. The Gaussian-shaped field of view was applied to the pencil beam simulations (blue) to simulate CRISTA profiles (red) (examples of the FOV function are centred on the cloud top at 12 and $13 \mathrm{~km}$ ). The superimposed numbers indicate the maximum errors in $\mathrm{CTH}, \mathrm{dCTH}=[$ no detection, $-0.30,0.36$, $0.81] \mathrm{km}$ (left), and $\mathrm{dCTH}=[-0.56,0.53,0.94,1.28] \mathrm{km}$ (right) for the corresponding CI threshold values $[1.2,2,3,4]$ applied in the cloud detection.

or slightly greater than the typical median values (Krämer et al., 2009) in the corresponding temperature range of the CRISTA measurements. Consequently, it is very likely that the CRISTA statistics also include a certain amount of underestimated CTHs of optically very thin clouds (IWC $<3$ ppmv).

Uncertainties in $\mathrm{CTH}$ determination from broken cloud segments along the line of sight in combination with the horizontal integration of the limb information and from the crosstrack extension of the FOV (30 arcmin, $\sim 15 \mathrm{~km})$ are not considered in the present analysis. For the combination of realistic limb ray tracing through highly resolved 2-D IWC fields from ECMWF analyses and RTM calculation, Spang et al. (2012) showed that, due to the integrated view of the limb sounder, significant differences in the retrieved cloud top height are not expected for two clouds with constant ADP. For example, a large IWC concentrated over a short horizontal distance or even multiple cloud fragments and a low IWC distributed homogeneously over a large horizontal distance result in very similar vertical CI profiles and corresponding CTHs. The study of Spang et al. (2012) showed that the size of the FOV and the location of the CTH in the FOV are the driving factors for the CTH error. However, due to the limb geometry, cloud inhomogeneities along the line of sight can result in an underestimation of the $\mathrm{CTH}$ with respect to the true $\mathrm{CTH}$. If the cloud segment is placed significantly in front or behind the tangent point (> $150 \mathrm{~km}$ for a FOV of $1.5 \mathrm{~km}$ ), and consequently at higher altitudes, then the retrieved $\mathrm{CTH}$ will be negatively biased. This error would, therefore, not explain the cloud observation above the tropopause.

\subsection{Radiosonde data}

In this study we used the radiosonde station composite data from the University of Wyoming, Department of At- mospheric Science. For August 1997, a time period embedding the complete CRISTA-2 mission, around 5000 radiosonde launches were available for coincident comparison of tropopause location with respect to CTHs from CRISTA and for the global validation of an improved tropopause determination with the ERA Interim data set (Sect. 2.5) at midand high northern latitudes. Figure 2 illustrates a coincident radiosonde temperature, relative humidity $(\mathrm{RH})$, and ice saturation temperature profile in comparison to the CRISTA cloud index profile. The cold point tropopause is clearly visible in the blue temperature profile. The horizontal lines indicate the retrieved $\mathrm{CTH}$ from $\mathrm{CI}$ and lapse rate tropopause based on coincident ERA Interim temperatures (details see Sect. 2.5). Usually radiosonde RH measurements around the tropopause have a low accuracy and act more like a qualitative measure of humidity. Nevertheless, RH and the ice saturation temperature profile indicate atmospheric conditions around the tropopause that allow for the existence of ice. This is in coincidence with the slightly higher cloud layer detected by CRISTA, where CTH and tropopause height (TPH) suggest a cloud above the local tropopause.

\subsection{Improved determination of the lapse rate tropopause for ERA Interim}

Accurate tropopause height determination is crucial for the location of cloud events with respect to the tropopause as PM2011 already showed for the CALIPSO cloud detection. For our analyses we used the ERA Interim reanalysis data on hybrid coordinates (Dee et al., 2011) with the original model resolution (60 levels and 600-1000 $\mathrm{m}$ resolution around the tropopause) for the computation of the tropopause height. A three-step approach is applied to the data. (1) For each CRISTA tangent height, the surrounding four ERA temperature and geopotential height profiles are determined. Then 
the lapse rate tropopause was defined for each profile as the lowest pressure (altitude) level at which the lapse rate is $2 \mathrm{~K} \mathrm{~km}^{-1}$ or less. The lapse rate should not exceed this threshold for the next-higher levels within $2 \mathrm{~km}$ (WMO, 1957). The vertical resolution of the retrieved TPH cannot be better than the vertical grid resolution of the temperature data and, hence, can produce a significant positive bias for analyses with tropopause related altitude coordinates (PM2011). In step (2) we applied a vertical spline interpolation with $30 \mathrm{~m}$ vertical resolution to the temperature profile around the actual TPH of step 1 and repeated the TPH computation with the artificially higher vertical resolution. Finally, in step (3) the weighted mean with distance of the four surrounding grid points of the observation point now represents the so-called high-resolution tropopause height $\left(\mathrm{TPH}_{\mathrm{hr}}\right)$. By this approach to tropopause determination a more realistic lapse rate tropopause was found because the single TPH values were not attached to the altitude grid points of the analysis data anymore.

Comparisons with the radiosonde data set for August 1997 show a good correspondence between the $\mathrm{TPH}_{\mathrm{hr}}$ and the lapse rate tropopause of the radiosonde for the coincidences with CRISTA profiles (see also Fig. 2). A statistical analysis of the difference in TPH between 5304 sonde profiles in the latitude range $30^{\circ} \mathrm{N}$ to $80^{\circ} \mathrm{N}$ and the ERA Interim-based $\mathrm{TPH}_{\mathrm{hr}}$ for August 1997 showed a mean difference of $15 \mathrm{~m}$ and a standard deviation of $650 \mathrm{~m}$. The latter value is exactly the same value as found in the analysis of PM2011 for a comparison between radiosonde and National Center of Environmental Prediction Global Forecast System (GFS) data for the June-July-August season in 2007. The good correspondence gives us confidence that the described $\mathrm{TPH}_{\mathrm{hr}}$ is the best possible and reliable approach for a tropopause determination for each CRISTA profile. In addition, the standard deviation of the differences appears to be a realistic estimate of the uncertainty of $\mathrm{TPH}_{\mathrm{hr}}$.

\section{CRISTA cloud top height occurrence with respect to the tropopause}

\subsection{Tropopause derived from radiosonde data}

A comparison of tropopause heights determined from radiosonde measurements with the CTHs detected in the tropopause region allows a first quantitative assessment of the indication for the frequent observation of optically thin clouds by CRISTA in the LMS, as illustrated in Fig. 1. Coincidence criteria consisting of a miss time of $2 \mathrm{~h}$ and miss distance of $200 \mathrm{~km}$ were chosen to minimise uncertainties in the comparison. For $158 \mathrm{CTH}$ detections close to the tropopause and north of $40^{\circ} \mathrm{N}$ (with $\mathrm{CI}_{\text {thres }}=3, \mathrm{CTH}-\mathrm{TPH}>-500 \mathrm{~m}$, and TPH defined from co-located ERA Interim temperatures), we found 188 coincident radiosonde profiles. The tropopause of 62 radiosonde profiles $(\sim 33 \%)$ was identi- fied more than $500 \mathrm{~m}$ below the coincident CTH of CRISTA. This indicates a remarkable fraction of clouds well above the tropopause and emphasises the question of whether these high-altitude clouds in the LMS are a common feature or a rare occurrence. However, the number of good coincidences between CRISTA and radiosonde measurements with respect to adequate miss time and distance criteria is only limited and allows no profound conclusions on this question. A statistical analysis of all cloud observed in the tropopause region together with the co-located tropopause heights based on ERA Interim may solve this problem.

\subsection{Statistical analysis with tropopause derived from ERA Interim}

For the statistical analysis of cloud occurrences around the tropopause, we choose a vertical coordinate independent of the temporal and spatial location of the tropopause. Therefore, thermal tropopause relative coordinates are, in the following, applied in a similar way to PM2011. These coordinates are used extensively in chemical tracer analyses (e.g. Tuck et al., 1997; Pan et al., 2007; Kunz et al., 2013) and temperature profile analyses (e.g. Birner et al., 2006). The actual distance of a detected CTH to the tropopause is defined by $\Delta_{\mathrm{CTH}}=\mathrm{CTH}_{i}-\mathrm{TPH}_{i}$, where the index $i$ is attributed to an individual measurement profile. In order to display results, it is often more helpful to adjust the reference altitude to the mean tropopause height $\left(\mathrm{TPH}_{\text {mean }}\right)$. The tropopause related altitude $Z_{\mathrm{r}}$ is then defined by

$Z_{\mathrm{r}}=\bar{Z}_{\text {trop }}+\left(Z-Z_{\text {trop }}\right)$,

where $\mathrm{Z}$ is the observation altitude or the $\mathrm{CTH}, Z_{\text {trop }}$ the individual tropopause, and $\bar{Z}_{\text {trop }}$ for example a daily or monthly zonal mean tropopause. Here, we use the zonal mean tropopause during the CRISTA-2 measurement period for $\bar{Z}_{\text {trop }}$. Fig. 4 presents the results of CTH height occurrence frequencies (COF) in respect to the single-profile tropopause location defined by the approach above and a vertical grid size of $0.5 \mathrm{~km}$. Latitude bands covering the whole Northern Hemisphere observations by CRISTA have been defined for the tropical $\left(0-20^{\circ} \mathrm{N}\right)$, subtropical $\left(20-40^{\circ} \mathrm{N}\right)$, mid- $\left(40-60^{\circ} \mathrm{N}\right)$, and high latitudes $\left(60-75^{\circ} \mathrm{N}\right)$. The vertical distributions are very different for the various latitude bands. A joint feature is the location of the maximum in $\mathrm{COF}$ in a layer 0.75 to $1.25 \mathrm{~km}$ below the tropopause for almost all latitude bands. In part, this is caused by the limb geometry. The probability of detecting a cloud along the line of sight located above the actual tangent height is enhanced by penetrating deeper into the troposphere. This effect causes artificially overestimated COFs below the real maximum in the COF distribution and is a large bias especially in the tropics. Here, cloud systems that only extended a little in horizontal direction and are patchily distributed $(<50 \mathrm{~km}$, e.g. caused by deep convection) generate unrealistic high COFs in limb 

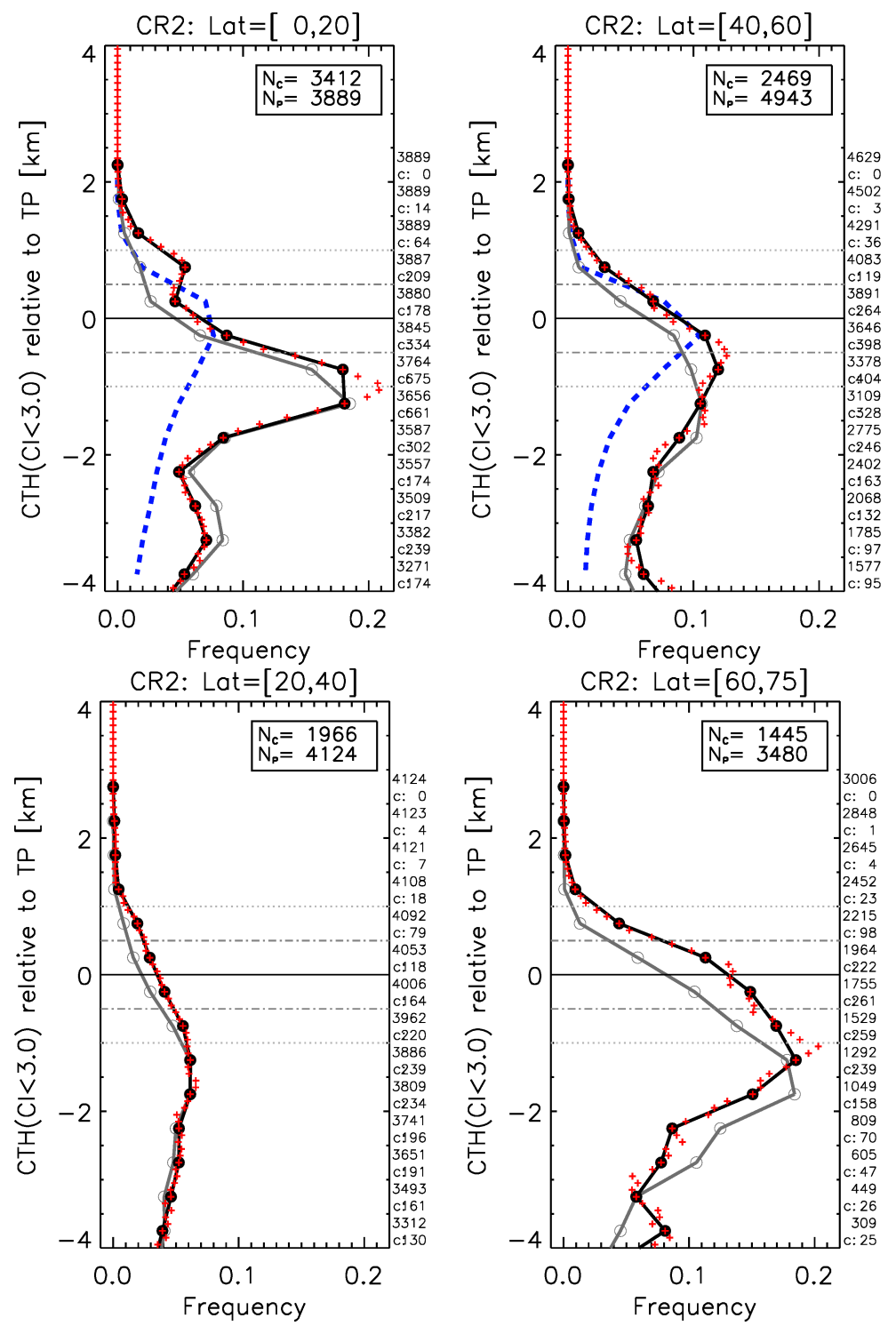

Figure 4. Cloud occurrence frequencies of CTHs relative to the tropopause for four latitude bands and the two detection thresholds $\mathrm{CI}_{\text {thres }}=2$ (grey circles) and $\mathrm{CI}_{\text {thres }}=3$ (black dots). The numbers on the right $y$ axis highlight the number of observations (top number) and the number of CTH counts (c:) in the corresponding altitude grid box $(500 \mathrm{~m})$ for $\mathrm{CI}_{\text {thres }}=3$. The blue dashed line in the top two figures represents the JJA mean COF values for CALIPSO from June 2006 to May 2010 (taken from Fig. 10 in PM2011). Uncertainty limits of \pm 0.5 and 1 km are presented by the horizontal lines. Red symbols represent a $100 \mathrm{~m}$ running mean statistic of $500 \mathrm{~m}$ vertical boxes.

observations (Kent et al., 1997; Spang et al., 2012). Note that CTHs assigned to such observations are actually biased low.

Only the subtropics show the COF maximum at slightly lower altitudes. However, more remarkably, generally very low COF values are found around the tropopause compared to the three other latitude bands. This local minimum at 20$40^{\circ}$ latitude in cloud probability has been already observed in various limb sounder observations around the tropopause (e.g. Wang et al., 1996; Spang et al., 2002, 2012).

Figure 4 presents the COF values for both CI threshold values. The frequencies for $\mathrm{CI}_{\text {thres }}=3$ are systemati- cally higher than for the less sensitive threshold $\mathrm{CI}_{\text {thres }}=2$, and more clouds are detected well above the predefined tropopause and also above the maximum in the COF distribution. For the more sensitive detection method $\mathrm{CI}_{\text {thres }}=3$, a COF of $3 \%$ and $4 \%$ (217 events in total) is found in the altitude grid box $500-1000 \mathrm{~m}$ for mid- and high latitudes respectively. Even in the $1000-1500 \mathrm{~m}$ grid box above the tropopause, COFs of $\sim 1 \%$ are observed in both latitude bands (59 events). These COF values above the tropopause indicate significantly larger occurrence rates than found in ground-based lidar observations (e.g. Noel and Haeffelin, 
2007; Rolf, 2013). The typically observed frequencies of 4 $10 \%$ of cross-tropopause cirrus are normalised to the total number of lidar profiles with cirrus clouds and not to the total number of observations (cloudy and non-cloudy) as for the satellite data. An equivalent approach would result in significantly smaller COF values for the lidar measurements.

In addition, the tropics show a pronounced local maximum well above the tropopause for $\mathrm{CI}_{\text {thres }}=3$. The $100 \mathrm{~m}$ running mean statistic of $500 \mathrm{~m}$ grid boxes (red symbols) indicates that the feature is not a sampling artefact caused by an interplay of the measurement altitudes with the vertical gridding of the COF analysis.

Exceptional events such as wildfires with pyro-convection are potential sources for unexpected enhanced UTLS aerosol loads (e.g. Fromm et al., 2010) and may cause the unexpected secondary maximum above the tropical tropopause in the CRISTA COF results. High fire activity was observed during the CRISTA mission and in the following months over Borneo, caused by the strong 1997/8 El Niño (e.g. Wooster et al., 2012). We checked the longitudinal distribution for the tropical CTH events above the tropopause but found no specific clustering of these events above the Borneo region. In contrast, the observed regions are in line with the typical regions for high subvisual cirrus cloud occurrence in the tropical tropopause region (e.g. Wang et al., 1996). For summer conditions, these are the warm tropical landmasses and the Micronesia area - the so-called warm-pool region. Due to the specific El Niño conditions, the latter region was extended in the direction of the middle of the Pacific (e.g. Spang et al., 2002), which is also observed in the CRISTA cloud distribution above the tropopause. The tropical secondary maximum has so far not been observed by other sensors. Based on the data investigated here, we cannot decide whether the occurrence of subvisual cirrus well above the tropopause is a regular feature or a particular event during the CRISTA mission.

\subsection{Statistical tests of cloud top occurrence distribution}

We have investigated in detail how the measurement uncertainties of the tangent point altitude, tropopause height, and cloud top height (Sect. 2) might influence or even falsify the COF statistics. Where TPH and tangent altitude errors are well described by a Gaussian distribution (with corresponding standard deviations), the CTH error $\left(\Delta_{\mathrm{CTH}}\right)$ caused by the vertical FOV effect for optically thick clouds acts like a positive bias in the cloud top height determination.

Monte Carlo (MC) simulations with the CRISTA measurement ensemble of cloudy and non-cloudy profiles have been performed taking into account (a) statistical and (b) systematic error sources. For both types of simulations all CTHs above the tropopause were excluded from the data set and the remaining CTH observations have been modified by a randomly distributed statistical uncertainty or a systematic positive offset value with a Gaussian amplitude. The results show that statistical (noise) errors like the TPH uncertainty with $\sigma_{\mathrm{TPH}}=650 \mathrm{~m}$ or even an overestimated value of $1000 \mathrm{~m}$ cannot reproduce the measured vertical COF distribution and cannot create the relatively large COFs observed above the tropopause.

In order to test the systematic errors, we applied, to all CTH observations below the tropopause, an FOV-like, Gaussian-shaped, and only positively offset distribution. This approach is equivalent to the assumption that all clouds below the tropopause are optically thick (upper limit), create a positive offset, and are detected with the randomly distributed observation heights of CRISTA. The results for $\left|\sigma_{\mathrm{FOV}}\right|=750 \mathrm{~m}$, a larger value than the real CRISTA $\sigma_{\mathrm{FOV}}=$ $625 \mathrm{~m}$, show comparable COF distributions for mid- and high latitudes and can create similar COF values above the tropopause as the original statistic. Larger $\left|\sigma_{\mathrm{FOV}}\right|$ produces overestimated COF values well above the tropopause $(>1.5 \mathrm{~km})$, significant underestimates below the tropopause, and can be excluded. Surprisingly, the MC simulations were not able to reproduce the tropical COF distribution with the positive-bias approach. These two negative tests, large $\left|\sigma_{\mathrm{FOV}}\right|$ and irreproducible tropical COF distribution, are additional constraints for a systematic and large FOV effect above the tropopause. In addition, it is very unlikely that all clouds around the tropopause are optically thick (only $<50 \%$, see Sect. 2.3). Consequently, it is very unlikely that this type of cloud is responsible for an artificial enhancement in COF above the tropopause like that observed by CRISTA in Fig. 4.

An additional and substantial argument against a large systematic FOV effect is the different behaviour between tropical and mid-/high latitudes in the measurements compared to the simulations. A positive bias for optically thick clouds should modify the pronounced maximum peak $1 \mathrm{~km}$ below the tropical tropopause in the following way, and this is confirmed in the MC simulations: the observations would show a broader distribution and a significant extent of enhanced $\mathrm{COF}$ values in the direction of higher altitudes similar to the mid- and high latitudes. However, this behaviour is not observed in the tropical measurements (Fig. 4a). A shift to higher altitudes can be reproduced in the error simulations with $\left|\sigma_{\mathrm{FOV}}\right|=750 \mathrm{~m}$, but, by contrast, it creates strongly enhanced COFs just below tropopause and reduced values below. The overall effect in the simulations, a positive shift of the whole distribution, is not observed in the original data.

In conclusion, taken all uncertainties into account, the CRISTA COF distribution indicates a significant amount of cirrus cloud observations in the lowermost stratosphere. To our knowledge, this is the first time such findings are reported for spaceborne limb measurements.

\subsection{Comparison with SAGE II}

The Stratospheric Aerosol and Gas Experiment II (SAGE II) instrument is a limb sounder with a vertical resolution and sampling of $0.5 \mathrm{~km}$ (e.g. Wang et al., 1996). The solar occultation technique only allows measurements of $\sim 30$ pro- 
files per day, and, consequently, significantly larger time periods than for CRISTA are necessary for a comparison of global cloud statistics. First comparisons between CRISTA cloud observations and subvisual cirrus cloud statistics retrieved from SAGE (Wang et al., 1996) have been presented in Spang et al. (2002). CRISTA showed slightly smaller cloud occurrence frequencies in the tropopause region than SAGE II. In the analyses, a $\mathrm{CI}_{\text {thres }}$ of 2 was applied to the data, which missed optically thinner clouds in the CRISTA measurements (about 2-5\% more CTHs are observed in the LMS for $\mathrm{CI}_{\text {thres }}=3$ instead of $\mathrm{CI}_{\text {thres }}=2$ at a certain altitude bin; Fig. 4). For summer 1997 (June, July, August) the zonal mean occurrence frequencies of SAGE II showed occurrence frequencies of up to $10-15 \%$ above the midlatitude mean tropopause. This is in line with analyses by Wang et al. (1996) for the SAGE II 1985-1990 climatology; monthly time series and multiannual means (Plate 6, Fig. 3) show similar values above the tropopause. These frequencies are even larger than the COFs in the actual CRISTA analyses (maximum 10\%). However, a quantitative comparison of both analyses is difficult. Here, we present CTH occurrence frequencies instead of cloud occurrence frequencies, where cloud detections below the CTH are considered as well and result in higher occurrence frequencies. In addition, the former analyses have not considered tropopause related coordinates (Sect. 3.2), which may cause a systematic overestimation in occurrence frequencies above the tropopause.

\subsection{Comparison with ice supersaturation measurements}

The existence of ice supersaturated regions (ISSR) is a precondition for the formation of cirrus clouds. ISSRs have similar vertical and horizontal scales and occurrence distribution to SVC (e.g. Gierens et al., 2000; Spichtinger et al., 2003a) and are observed with various ground-, air-, and spaceborne sensors. Statistics in respect to the tropopause location are less frequently reported. Spichtinger et al. (2003a) showed ISSRs in the lowermost stratosphere for $6.2 \%$ of the regular balloon launches over Lindenberg, Germany $\left(52.22^{\circ} \mathrm{N}\right.$, $14.12^{\circ} \mathrm{E}$ ). This amount fits in well with the COFs observed by CRISTA at midlatitudes. However, taking into account that supersaturations greater than $100 \%$ are necessary for the homogeneous freezing of ice (Koop et al., 2000), the observed ISSR occurrence still seems too low to explain the large COFs observed by CRISTA.

Satellite observation of ISSR should allow a better comparison with the CRISTA COF results. Spichtinger et al. (2003b) showed very low occurrence frequencies in the midlatitude tropopause region (maximum $2-3 \%$ at $215 \mathrm{hPa}$ ) for satellite-based ISSR measurements with the Microwave Limb Sounder (MLS) instrument. The limited vertical resolution $(\sim 3 \mathrm{~km})$ of MLS and integration along the line of sight $(\sim 200 \mathrm{~km})$ will reduce the detection sensitivity for ISSR by a factor of 0.2 compared to data from the Mea- surements of OZone and water vapour in Airbus In-service airCraft experiment (MOZAIC). Gierens et al. (2000) found that the MOZAIC flights from 1995 to 1997 spent about $15 \%$ of their time in ice supersaturated air masses. Stratospheric ISSR events were only rarely found in the MLS data, but only a crude tropopause determination was applied in the analyses and may create biases in the results (Spichtinger et al., 2003b). More recent analyses use MOZAIC data in combination with Atmospheric Infrared Sounder (AIRS) specific humidity and cloud data to estimate occurrence frequencies of ice supersaturation (Lamquin et al., 2012). The authors find significantly larger frequencies than in the MLS analysis in the midlatitude tropopause region (20-30\%) and indications of ISSR occurrence of $10-20 \%$ in the midlatitude zonal mean tropopause and above (Fig. 11). These numbers would favour the more frequent formation of cirrus clouds in the LMS.

\subsection{Comparison with ground-based lidar measurements}

There are a couple of recent studies on the properties of cirrus clouds at midlatitudes based on ground-based lidar observations (Dupont et al., 2010; Hoareau et al., 2013; Dionisi et al., 2013). The analyses show a significant and large proportion of optically thin cirrus clouds in the upper troposphere ( $42 \%$ of all profiles, Hoareau et al., 2013), in the tropopause region (30\% of all and $9 \%$ of the cloudy profiles, Dionisi et al., 2013), or, even more precisely localised, above the tropopause (up $10 \%$ of all cloudy profiles, Rolf, 2013). However, there is only one study by Noel and Haeffelin (2007) of a longer time series with detailed cirrus analysis with respect to the tropopause. Measurements were provided by a lidar system located at the Site Instrumental de Recherche par Télédétection Atmosphérique (SIRTA) observatory $\left(48.71^{\circ} \mathrm{N}, 2.21^{\circ} \mathrm{E}\right)$. Tropopause characteristics are determined by a nearby radiosonde station. Between 2002 and 2006, the cloud measurements show $5 \%$ cross-tropopause cirrus (cloud base below and cloud top above the tropopause) and $2 \%$ inter-tropopause (cloud base above tropopause) events. In total, $2.5 \%$ of all observations (cloudy and non-cloudy profiles) show cloud tops above the tropopause, a significantly smaller number than the integrated above-tropopause COFs of $\sim 10 \%$ for midlatitudes found in the CRISTA data (Fig. 4) but very similar to the COF value of $3 \%$ for cloud events significantly above the tropopause $(\mathrm{CTH}-\mathrm{TPH}>0.5 \mathrm{~km})$.

\subsection{Comparison with the CALIPSO lidar}

For a brief comparison with the CALIOP lidar on CALIPSO, results from PM2011 are superimposed in Fig. 4 for tropical and midlatitude observations. For midlatitudes, CRISTA and CALIOP show very similar results in the tropopause even though the time period and observation geometry are rather 
different (7-day mean in August 1997 from limb measurements versus multiannual seasonal mean from June 2008 to May 2010 from nadir measurements). In this region, even the absolute COF values are in close agreement. However, in the grid boxes 500-1000 $\mathrm{m}$ and 1000-1500 $\mathrm{m}$ above the tropopause, CRISTA detected $\sim 2$ times more clouds than CALIPSO. Below the tropopause, the limb sounder statistic shows a substantially larger maximum in COF. This is primarily due to the long limb path integration and the artificially enhanced number of cloud detections well below the tropopause by higher-altitude cloud fragments along the line of sight, and it is only secondarily due to the better detection sensitivity for horizontally extended clouds in the limb compared to the short nadir viewing direction.

The tropical distribution looks different, especially below the tropopause, where again the overestimation due the limb geometry plays a role. At the tropopause $( \pm 500 \mathrm{~m})$, where this effect is negligible, both instruments show similar COFs. Well above the tropopause (500 to $1500 \mathrm{~m}$ ), CRISTA COFs are again significantly higher than CALIPSO and indicate the presence of optically very thin clouds, which are currently not detected in the CALIPSO data products (see also Sect. 1). It should be noted that the CALIOP instrument may have observed these clouds, but the current detection threshold of the operational data products is not capable of detecting ultra-thin cirrus clouds. This was already shown by Davis et al. (2011) in a validation study with airborne lidar and in situ particle measurements. Modified detection schemes with larger horizontal averaging of the high-resolution level 1 profile data of CALIOP (e.g. 30 or $50 \mathrm{~km}$ instead of currently $5 \mathrm{~km}$ ) may substantially improve the detection sensitivity for ultra-thin cirrus clouds (M. Vaughan, personal communication). The current detection limit for cirrus clouds averaged horizontally to $5 \mathrm{~km}$ for the $532 \mathrm{~nm}$ backscatter channel results in a retrieved extinction value of 0.005 to $0.02 \mathrm{~km}^{-1}$ (Avery et al., 2012), which represents an equivalent IWC of 0.1 to $4 \times 10^{-3} \mathrm{~g} \mathrm{~m}^{-3}$.

However, the IR limb sounder detection limit can be considerably better, depending on the horizontal extent of the cloud and depending how much of the vertical field of view is covered by the cloud. The $\mathrm{ADP}_{\text {thres }}$ of $10^{7} \mu \mathrm{m} \mathrm{cm} \mathrm{cm}^{-2}$ (Sect. 2.2) is equivalent to an IWC of $10^{-6} \mathrm{~g} \mathrm{~m}^{-3}$ for a cloud layer with $100 \mathrm{~km}$ horizontal times $1.5 \mathrm{~km}$ vertical extent (by assuming a constant $R_{\text {eff }}$ of $10 \mu \mathrm{m}$ for the ice particles, see Eqs. (1) and (2)). This is about 2 orders of magnitude better than the current CALIOP product. A thinner cloud layer will enhance the detection threshold in an almost linear way, depending on where the cloud layer is placed in the FOV of CRISTA. Consequently, a cloud fragment of $3 \mathrm{~km}$ horizontal times $0.5 \mathrm{~km}$ vertical extent is still detectable by the CRISTA instrument if the cloud contains a mean IWC $>10^{-4} \mathrm{~g} \mathrm{~m}^{-3}$, a value of the size of or even smaller than the current IWC detection limit of CALIOP.

\section{Horizontal distribution of water vapour and clouds in the UTLS}

\subsection{Cloud top height distributions}

During CRISTA-2, 4 days have a measurement net dense enough for hemispheric analyses of horizontal structures in cloud and trace gas distributions. Figure 5 presents the daily cloud top height distribution detected with the algorithms described in Sect. 2.2 for 10 to 13 August at midnight $\pm 12 \mathrm{~h}$. Potential temperature $(\Theta)$ has been used as a vertical coordinate, and CTHs in kilometres are converted to $\Theta$ by coincident ERA Interim temperature and geopotential height information. Only clouds detected in the altitude range of 330 to $370 \mathrm{~K}$ are presented, an atmospheric layer usually located in the lower half of the LMS at mid- and high latitudes and, clearly, in the upper troposphere and tropopause region for the tropics and subtropics.

The observations frequently show events with high cloudtop- $\Theta\left(\Theta_{\mathrm{CTH}}\right)$ events in regions where elongated PV contours as well as horizontal winds (not shown) suggest strong horizontal transport and mixing processes extending from midlatitudes $\left(\sim 40^{\circ} \mathrm{N}\right)$ to high northern latitudes. The main regions are over the eastern Pacific, extending towards Alaska, the north-eastern US towards Greenland, from the North Atlantic and central Europe towards northern Scandinavia and the Baltic region, and from China towards Siberia. High-altitude clouds are observed up to the northern edge of the CRISTA measurements at $74^{\circ} \mathrm{N}$ (e.g. over northern Scandinavia and the Baltic Sea on 10 August). During the 4 days of observations, the frequency for high $\Theta_{\mathrm{CTH}}(>350 \mathrm{~K})$ events north of the subtropical jet region seems to decline.

The highest detected $\Theta_{\mathrm{CTH}}(350-360 \mathrm{~K})$ are in most cases above the local tropopause, indicating an origin of the detected cloudy air masses in the LMS. CTHs below $350 \mathrm{~K}$ in regions dominated by high CTHs (e.g. in the ScandinaviaBaltic-Sea streamer) may be caused by a "real" loweraltitude tropospheric cloud but can also indicate underestimated CTHs caused by the vertical sampling of the CRISTA measurements. The constant $2 \mathrm{~km}$ vertical step size during CRISTA-2 in combination with a top that drifts slightly in altitude from one profile to the next with time and latitude results in significant differences in the absolute tangent height even between subsequent orbits (up to $1 \mathrm{~km}$ ) with close geographical co-location. Consequently, a large cloud structure with nearly constant CTH may be detected at different altitudes in two subsequent orbits at higher latitudes or in the tropics on the up and down legs of a single orbit.

\subsection{Water vapour measurements during CRISTA-2}

The horizontal distribution of the CRISTA water vapour at the $350 \mathrm{~K}$ isentrope is illustrated in Fig. 6 for the same days as in Fig. 5. For better visualisation the data of individual CRISTA $\mathrm{H}_{2} \mathrm{O}$ profiles have first been interpolated to a con- 

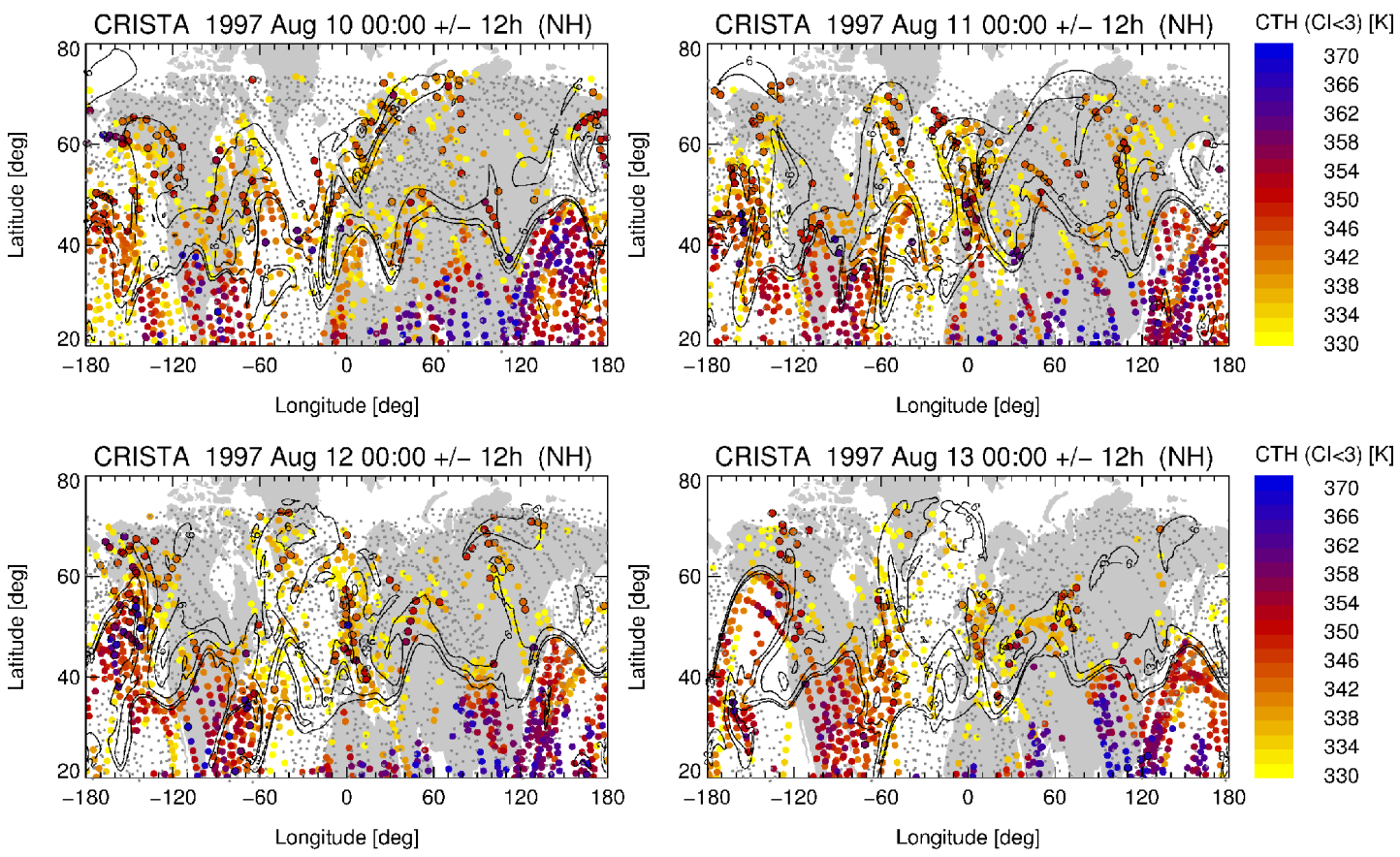

Figure 5. CRISTA-2 daily detection of cloud top heights on vertical $\Theta$-coordinates between 330 and $370 \mathrm{~K}$ (colour coded) from 10 to 13 August at 00:00 UTC $\pm 12 \mathrm{~h}$. Black circles around the coloured symbols mark CTH observation above the local tropopause. Potential vorticity contours for 2, 3, and 6 PVU are overlaid in black at midnight conditions. In addition, horizontal wind contours for 30 and $40 \mathrm{~m} \mathrm{~s}^{-1}$ (in green) highlight the subtropical jet as well as regions with fast horizontal transport at higher latitudes. Crosses mark non-cloudy profiles in the $\Theta$-range of 330 to $370 \mathrm{~K}$.
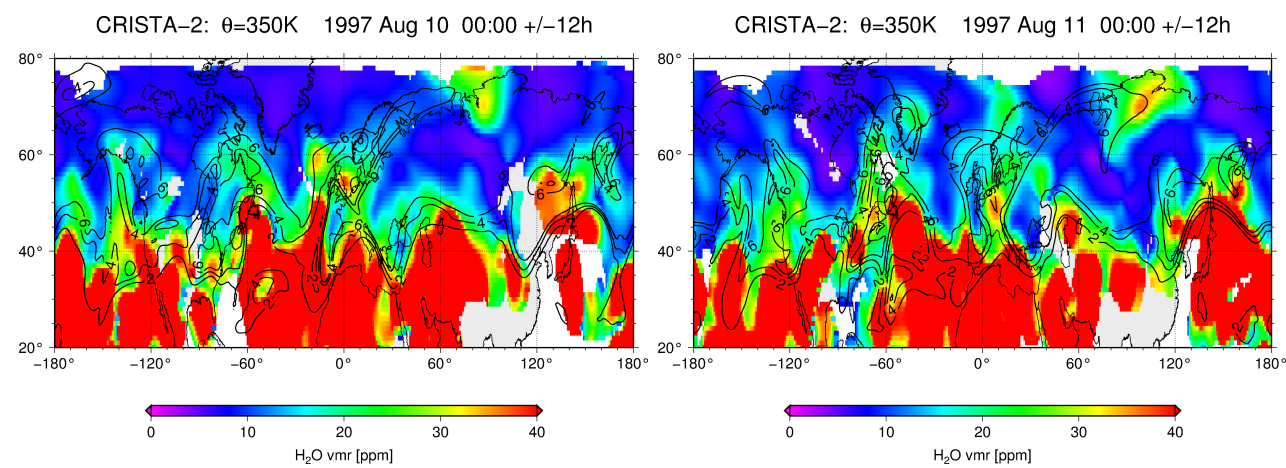

CRISTA-2: $\theta=350 \mathrm{~K} 1997$ Aug $1200: 00+/-12 \mathrm{~h}$
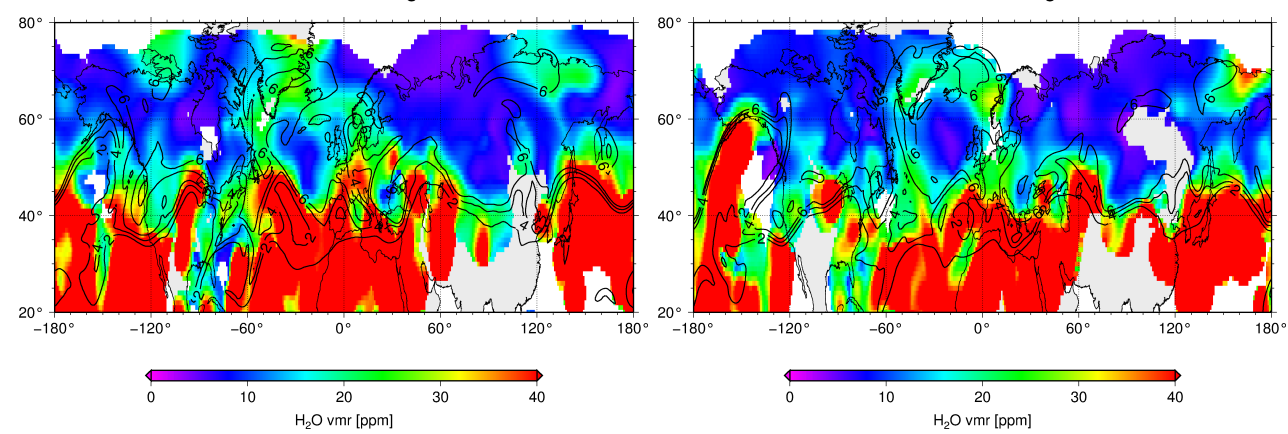

Figure 6. CRISTA 2 measurements of water vapour for 10 to 13 August at 00:00 UTC $\pm 12 \mathrm{~h}$. The asynoptic measurements are interpolated spatially to a regular grid (for details see text). In addition, PV contour lines of 2, 4, and 8 PVU are overlaid in black. White patches in the water distribution indicate data gaps due to clouds. 
stant $\Theta$ level (here $350 \mathrm{~K}$ ). Vertical interpolation around the tropopause and below always involves the risk that it may create some numerical diffusion and artificially enhanced water vapour mixing ratios at the grid level due to the strong exponential gradient in the mixing ratio profile below the tropopause. This effect was minimised by logarithmic interpolation. In a second step, a horizontal interpolation on a regular grid $\left(1^{\circ} \times 1^{\circ}\right)$ was performed by means of distanceweighted averaging. Data gaps in the tropics are mostly due to clouds.

The CRISTA water vapour measurements were validated with the Microwave Limb Sounder (MLS) and airborne in situ instruments (Offermann et al., 2002). The comparisons showed good agreement in the coincidence statistics and a retrieval accuracy of $10 \%$ was estimated for the data. The precision of the data is $8 \%$ for values $>10 \mathrm{ppmv}$ and $8-15 \%$ for smaller values (Schaeler et al., 2005). Consequently, the horizontal structures in Fig. 6 are reliable.

Transport of water vapour from the tropical troposphere into the LMS on the $350 \mathrm{~K}$ isentropic surface seems evident in Fig. 6. The figure shows water vapour values as observed by CRISTA- 2 on 10 to 13 August at midnight $\pm 12 \mathrm{~h}$. Rossby wave breaking events result in an erosion of the tropopause that can by identified by the cut-off of PV and water vapour contour lines over the Atlantic to Scandinavia and the Baltic Sea, over the eastern North Pacific towards Alaska or from the eastern US towards Greenland. The intense wave processes are accompanied by the fast isentropic transport of water vapour deep into the LMS. These horizontal structures of high water vapour nearly coincide with the "unusually" high CTH observation shown in Fig. 5.

The water vapour values do not include the locations of optically thicker cloud observations because a corresponding filter $(\mathrm{CI}<2)$ was applied before the retrieval. However, it is evident that cloudy areas are embedded in regions of relatively high water vapour values. More quantitative analyses exclusively from the satellite observations are difficult because for most cloudy CRISTA observations no adequate water retrieval is available.

\section{Comparison with the CLaMS model}

\subsection{The CLaMS model}

The Chemical Lagrangian Model of the Stratosphere (CLaMS; McKenna et al., 2002a, b; Konopka et al., 2007) is a chemistry transport model based on 3-D forward trajectories, describing the motion of air parcels. Additional to advection by winds, irreversible small-scale mixing between air parcels induced by the deformation of the large-scale flow is considered in the model (McKenna et al., 2002a; Konopka et al., 2004). The mixing intensity is controlled by the local Lyapunov coefficient of the flow, thus leading to stronger mixing in regions of large flow deformations. The sensitiv- ity of simulated UTLS water vapour on the intensity of this quantity is discussed by Riese et al. (2012). The model uses a hybrid of pressure and potential temperature as the vertical coordinate system first proposed by Mahowald et al. (2002).

\subsection{Model set-up}

The CLaMS simulation was started in mid-May 1997, 3 months in advance of the CRISTA observations, to give the model enough time for spin-up. The model was driven by 6hourly ERA Interim reanalyses with a mixing time step of $24 \mathrm{~h}$. The calculation of water vapour in CLaMS includes a simplified dehydration scheme, similar to that applied in von Hobe et al. (2011). Gas phase water in CLaMS is initialised at the beginning of the simulation, utilising the specific humidity taken from ERA Interim data. Boundaries are updated every CLaMS step from ERA Interim data as well. The lower boundary for this run is at $250 \mathrm{~K}$ with respect to the hybrid vertical coordinate, corresponding to approximately $500 \mathrm{hPa}$.

The formation of ice is parameterised either by using a fixed value of $100 \%$ for saturation over ice (a value commonly used) or by a temperature-dependent parameterisation for heterogeneous freezing (Krämer et al., 2009). The latter method was finally used in the model simulations presented below. This parameterisation results in saturation values between $120 \%$ and $140 \%$ for the temperature range from $180 \mathrm{~K}$ to $230 \mathrm{~K}$. Water vapour with values above these saturation levels is removed from the gas phase and added to the ice water content. Water vapour and ice water content are transported and mixed like any other tracer or chemical species. By assuming a uniform particle density and size distribution (Krämer et al., 2009), evaporation at $100 \%$ saturation and sedimentation of ice as well as parameterised processes such as re- and dehydration are considered, with the only exception of rehydration by formerly sedimented particles. For sedimentation the terminal settling velocity is calculated. The corresponding sedimentation length is compared with a characteristic height defined by the vertical resolution of the model around the tropopause $(\sim 650 \mathrm{~m}$ for this simulation), and the related fraction of ice is removed. This mechanism was successfully used for long-term studies with CLaMS (Ploeger et al., 2011, 2013). The horizontal resolution of the simulations is in the range of $70 \mathrm{~km}$.

\subsection{IWC and water vapour distribution in the model}

In a first step we investigated CLaMS model results for water vapour and ice water content on synoptic maps of isentropic surfaces like in Fig. 1. Afterwards model output is analysed by applying the instrument-specific limb geometry to the data, which is described in the next subsection.

In the examples of Fig. 1, isentropic surfaces of $\Theta=350 \mathrm{~K}$ are selected, which represent a nearly constant geometrical height with changing latitude, where isentropic transport can cross from the tropical UT into the midlatitude lower strato- 

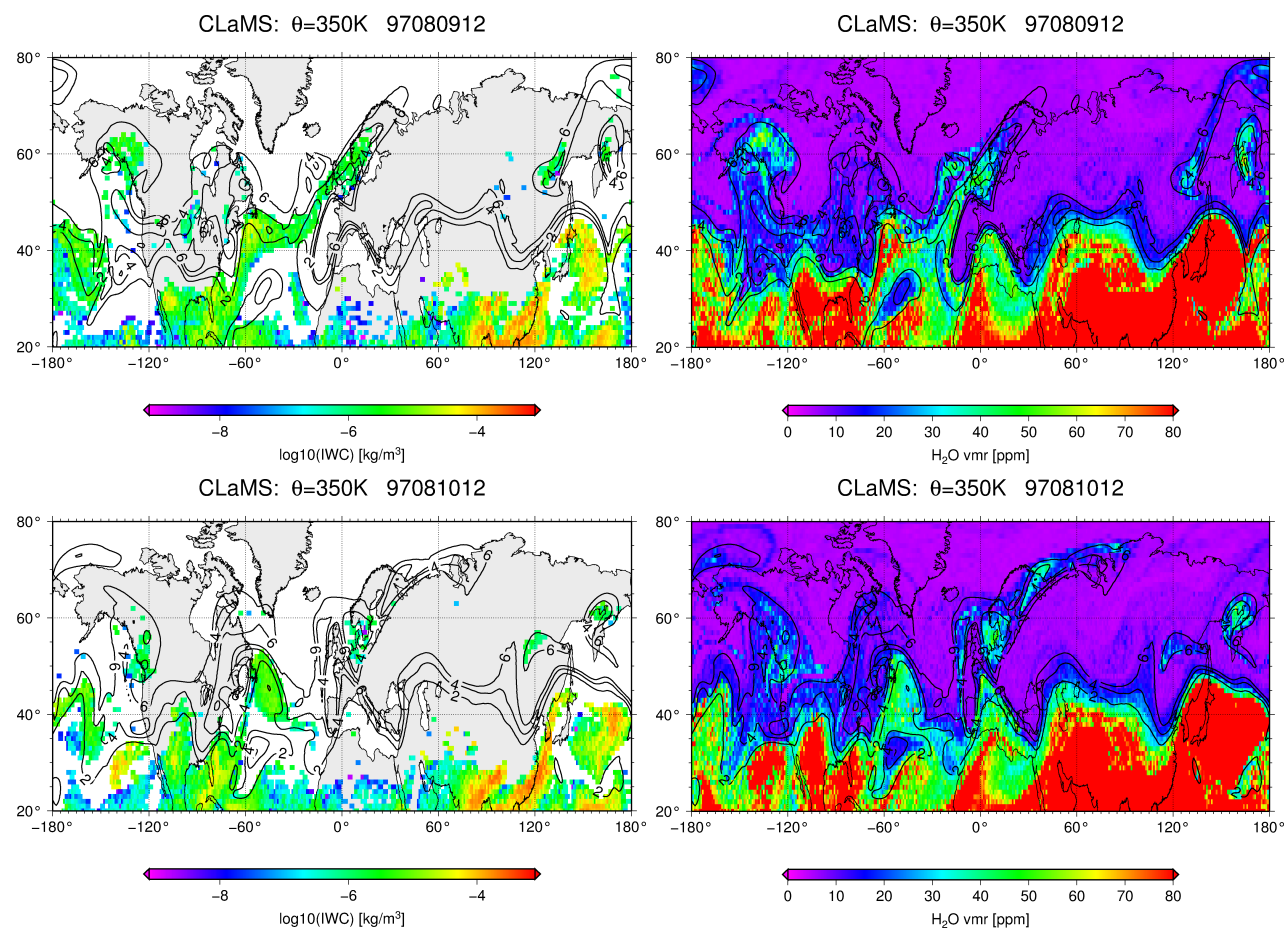

Figure 7. CLaMS model results of IWC (left) and water vapour (right) for meteorological input data based on ERA Interim; top row for 9 August at 12:00 UTC and bottom row for 10 August 1997. CLaMS irregular data are interpolated to a $1^{\circ} \times 1^{\circ}$ grid for the $350 \mathrm{~K}$ isentrope.

sphere. In Fig. 1 both IWC and water vapour show distinctive streamer structures on 2 successive days $(9$ and $10 \mathrm{Au}-$ gust). The streamers are elongated and spread out to midand high northern latitudes. Especially the water vapour distribution suggests that regions of high water vapour are separated from the subtropical jet region, as typically observed in PV fields during Rossby wave breaking events (e.g. Homeyer and Bowman, 2013). These subtropical air masses are transported to high latitudes, where they are mixed in. Afterwards, under favourable conditions, the formation of cirrus clouds might be possible. Fine structures of water vapour and IWC can be observed similar to and more finely structured than the superimposed PV contours. The IWC structures are less pronounced and indicate significantly less cloud formation at mid- and high latitudes in contrast to the CRISTA observations (Fig. 5).

\subsection{How to compare global model data and limb measurements}

For a quantitative comparison between the model data and limb measurements, it is crucial to take into account the observation geometry and to apply averaging kernels of the instrument to the model data. In an optimised but very expensive process, current investigations simulate the original measurement quantity of the instrument (e.g. here IR radiances) by a specific instrument simulator based on 3-D input parameters of a climate chemistry model (e.g. Bodas-Sacedo et al., 2011). This approach will reduce the uncertainties usually introduced by the complex retrieval process of the instrument target parameter (e.g. IWC, specific humidity, or other trace gases) and is used for the validation of climate models. The detailed consideration of the observation geometry is especially important for comparisons with cloud measurements in the limb (e.g. Spang et al., 2012). Therefore, we applied several processing steps for a better representation of two major instrument-specific effects of the CRISTA measurements.

In the first step, the temporal offsets between the asynoptic measurement times of the satellite and the synoptic time steps in the model output (every $24 \mathrm{~h}$ ) were compensated for. For this purpose, backward trajectories of all CRISTA observations below $25 \mathrm{~km}$ to the next synoptic model output time, usually every $24 \mathrm{~h}$ at 12:00 UTC, were computed. Starting from these synoptic locations, the cirrus module of CLaMS was run forward in time to the asynoptic time of the individual CRISTA observation. By this approach the formation and evaporation of ice clouds within a time frame of a maximum of $24 \mathrm{~h}$ between model output (12:00 UTC) and observation is taken into account.

Secondly, we implemented an integration of the signal along the line of sight. A limb ray tracing from the original position of the CRISTA satellite to the tangent point and the follow-on to deep space has been applied to sample the model data. In the case of CRISTA, the tangent height layer for the $1.5 \mathrm{~km}$ FOV has an extension of $\sim 280 \mathrm{~km}$. Deeper 
tropospheric observations result in effective path lengths (the path through the atmosphere where a cloud can occur) that are longe by a factor of 2-3 (e.g. in the tropics). In the tropics, for a tangent height at $10 \mathrm{~km}$, the maximum potential cloud occurrence altitude extends up to a height of $\sim 18 \mathrm{~km}$, and a corresponding line-of-sight segment of $\sim 640 \mathrm{~km}$ should be considered in the limb ray tracing.

Finally, we used the simulated IWC to compute the IWP for a CRISTA-like cloud detection in the CLaMS model fields. A $30 \mathrm{~km}$ step width along the line of sight over a distance of $\pm 1000 \mathrm{~km}$ with respect to the tangent point was chosen, which is in line with the horizontal resolution of the model. Then IWC CLAMS was interpolated on the lineof-sight grid locations. A CTH detection is defined when the first (top) line-of-sight beam of a CRISTA profile shows an $\mathrm{IWP}_{\mathrm{CLAMS}}>0$. The latter fact ignores any detection sensitivity threshold of the instrument and therefore represents an upper limit of what a CRISTA-like instrument would detect in the cloudy atmosphere modelled by CLaMS.

An example of the CRISTA-like limb IWP is given in Fig. 8. All tangent heights between the 330 and $370 \mathrm{~K}$ isentrope with IWP $>0$ are presented for 10 August 1997 at 00:00 UTC $\pm 12 \mathrm{~h}$. The results can be compared with Figs. 1 and $5 \mathrm{a}$, even though these figures show the CTH of a measured profile. For a perfect agreement between model and measurement, the CLaMS cloud detections should be exactly at the location where CRISTA observed a cloud. Obviously the model field of IWP shows a good agreement with the cloud occurrence observed by CRISTA. Similar regions show the occurrence of clouds at mid- and high latitudes. Some regions are extended more greatly in the observations than in the model (e.g. the east of the North Atlantic to Baltic Sea streamer, the extension over Alaska or over Kamchatka). However, there are also a few regions where the model shows clouds but the observation is cloud free. However, care should be taken in the comparison of model grid and instrument grid data. For example, when the interpolation onto the line of sight is performed, numerical errors can generate unrealistically enhanced IWC at altitudes and segments of the line of sight just above the highest grid points with modelled IWC $>0$. Due to the strong vertical gradients, this is especially a problem for IWC and water vapour. Although the comparison look promising, a more quantitative comparison shows that the generated CTHs from the modelled IWP are significantly lower than the observations (not shown) and usually do not reach the LMS (usually between 330 and $350 \mathrm{~K}$ and only a few events above; see also Sect. 5.5).

In addition, the model does not create optically very thin cloud layers (low IWP). The probability density function of the modelled IWP does not extend significantly below $20 \mathrm{~g} \mathrm{~m}^{-2}$, an indication that the model is not capable of producing optically and/or vertically very thin cirrus cloud layers, which are detectable by an IR limb sounder. Spang et al. (2012) already quantified the detection threshold for IWP

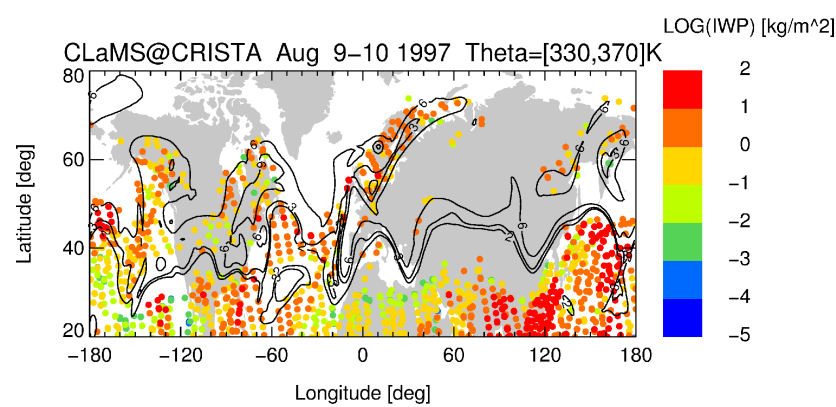

Figure 8. Limb ice water path based on derived from CLaMS IWC integrated along CRISTA line of sights for 10 August 1997 at 00:00 $\mathrm{UTC} \pm 12 \mathrm{~h}$ between the 330 and $370 \mathrm{~K}$ isentrope (for details see text). PV contours for 2, 3, and 6 PVU are superimposed.

to $\sim 0.3 \mathrm{~g} \mathrm{~m}^{-2}$. Such small values are rarely observed in the model output, where values rarely undercut the upper edge of sensitivity in the IWP retrievals of $\sim 20 \mathrm{~g} \mathrm{~m}^{-2}$ (larger IWP values cause optically thick spectra). This "high" bias in the modelled IWP is attributed to the freezing parameterisation in the cirrus module of CLaMS. After reaching the supersaturation threshold for ice formation, the whole water vapour fraction above $100 \%$ saturation over ice is converted to IWC. This approach is an upper limit for ice formation and can overestimate the "real" ice water content. As a result, the size of the particles can be over- or underestimated, which consequentially has a strong effect on the dehydration process.

\subsection{Zonal mean cloud occurrence frequencies}

For a more quantitative comparison of the cloud occurrence in the model and in the observations, we computed the zonal mean cloud top height occurrence frequency in tropopause related coordinates $Z_{\mathrm{r}}$ (see also Sect. 3). For the cloud detection in the model data any line of sight with IWP $>0$ is flagged as cloudy and, consequently, by this approach, the highest possible number of clouds will be detected. The zonal means over the whole mission are presented in Fig. 9. Overall, the distributions from the simulation and observation look very similar. They show a maximum in the tropics well below the tropopause in the observations and slightly higher in altitude and percentages in the model. In addition, a reduced activity in the subtropics for both data sets and very similar COFs around the mid- and high-latitude tropopause are found. However, the CRISTA measurements show substantially increased cloud occurrence frequencies at altitudes well above the tropopause for all latitude bands.

The differences in COF between observation and model are illustrated in Fig. 9c. Obviously the model overestimates the COF in the tropical upper troposphere and up to slightly above the tropopause, a region designated the tropical transition layer (Fueglistaler et al., 2009). Between the isentropic surfaces 350 and $360 \mathrm{~K}$, the region of overestimation is extended up to latitudes of $40^{\circ} \mathrm{N}$. At these altitudes horizontal 

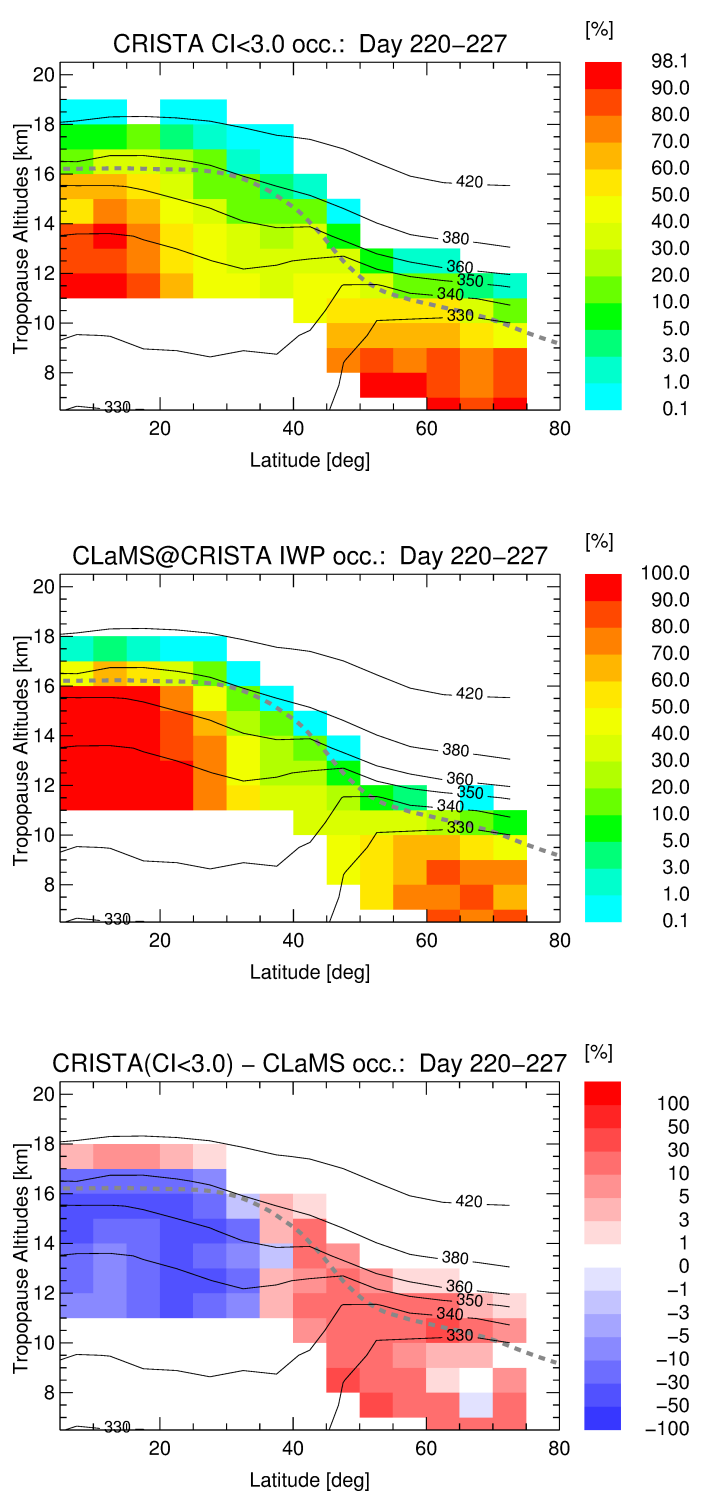

Figure 9. Cloud top height occurrence frequencies in tropopause related vertical coordinates for the complete measurement period (7 days) of CRISTA-2 (top) based on $\mathrm{CI}_{\text {thres }}=3$. The corresponding CLaMS model is sampled with the lines of sight of CRISTA, and cloud top detection is based on IWP $>0$ (middle). Differences in cloud top height occurrence frequency between CRISTA and CLaMS sampled with CRISTA are presented in the bottom diagram. Contours for zonal mean isentropes (black) and for the zonal mean tropopause altitude (dashed grey) are superimposed.

transport is possible from tropical and subtropical air masses with high water vapour mixing ratios into the LMS to midand higher latitudes. Since the subtropical jet acts as a transport barrier to meridional transport, this indicates a weakening of the subtropical jet, a condition typically coincident with RWB events in the jet region (Postel and Hitchmann, 1999). RWB events have been observed during the CRISTA2 mission, as illustrated in Fig. 5 and Fig. 6 by the devel-
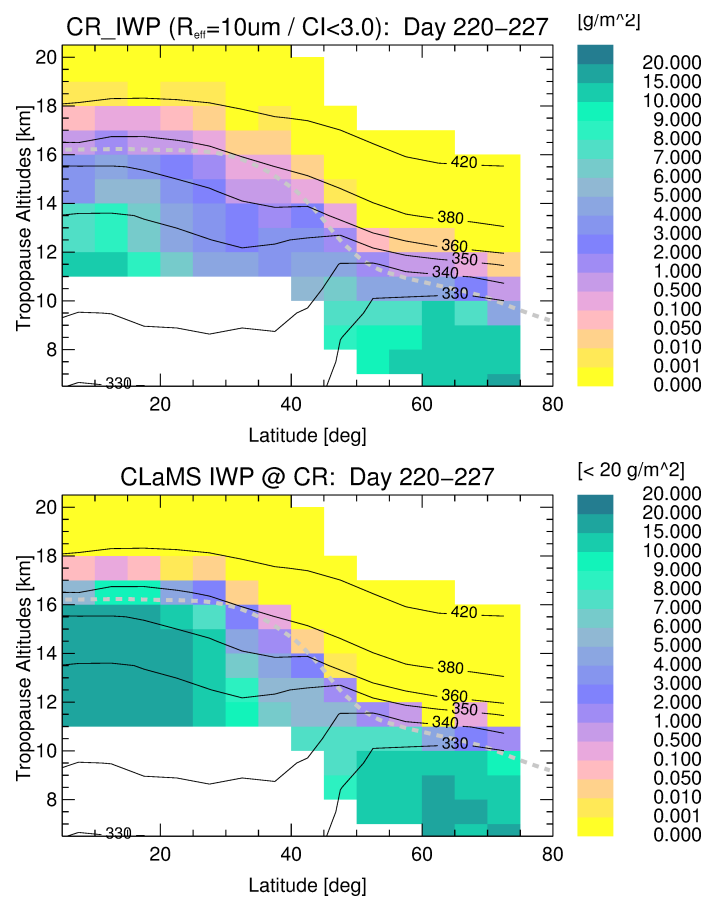

Figure 10. Zonal mean CRISTA limb IWP retrieved from CI (top) and from the CLaMS model (bottom) with a shortcut of IWP $_{\text {CLAMS }}>20 \mathrm{~g} \mathrm{~m}^{-2}$ at the upper detection sensitivity of CRISTA (right). For the computation of IWP $_{\mathrm{CR}}$, it is necessary to assume a constant effective radius for the ice particles $\left(R_{\mathrm{eff}}=10 \mu \mathrm{m}\right.$ is applied, see also Eq. (2)).

opment of the PV contours during the mission. Such events are very typical in summer at this altitude and latitude location (e.g. Gabriel and Peters, 2008, Homeyer and Bowman, 2013).

Above $360 \mathrm{~K}$ in the subtropics and north of $40^{\circ} \mathrm{N}$ in the tropopause and LMS region, CRISTA observations indicate higher COFs than the model and - as already presented in Fig. 4 - a large amount of high-altitude cloud occurrence in the LMS, which is only weakly present in the model calculations. This is caused by the cirrus module in CLaMS, which only includes a simplified approach to ice formation (mainly driven by temperature, the super saturation threshold in respect to ice, specific humidity, and IWC) and does not consider detailed microphysical background or constraint boundary conditions.

\subsection{Limb ice water path comparison}

This section presents the limb IWP estimated from CRISTA in comparison to CLaMS. As already outlined in Sect. 2.2, the parameters best suited to comparing model results with a limb measurement of microphysical information of cirrus cloud are the limb-integrated area density and ice water path. IWP CLAMS is computed from the model data following Eq. (2) by using the CLaMS air parcel information of 


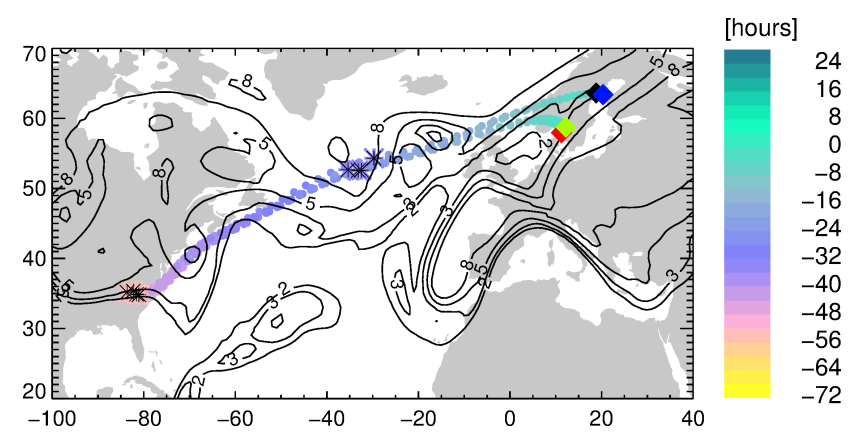

Figure 11. Geographical position of four forward trajectories from 7 August at 12:00 UTC to 9 August at 12:00 UTC (coloured dots) based on 2-day backward trajectories from CLaMS ice events over Scandinavia (IWC> 0 and altitudes above the tropopause) on $9 \mathrm{Au}-$ gust at 12:00 UTC (reference time for Fig. 12). CLaMS ice events are highlighted by coloured diamonds in red, green, blue, and black. Crosses mark the position on 7 and 8 August at 12:00 UTC. PV contours are presented at $\Theta=350 \mathrm{~K}$ for 9 August at 12:00 UTC.

IWC and the limb ray tracing described in section 5.4. The zonal mean IWP CRISTA $_{\text {and IWP }}$ CLAMS distributions presented in Fig. 10 show similar structures to the CTH occurrence frequencies (Fig. 9) but include all tangent heights with cloudy signals in the measurements (IWP $>0$ ) and in the observations ( $\mathrm{CI}<4$ equivalent to IWP $>\sim 10^{-3} \mathrm{~g} \mathrm{~m}^{-2}$ ) and not only the CTH locations. For the zonal mean calculation for CLaMS, we cut all IWP values greater than the upper retrieval limit down to IWP $=20 \mathrm{~g} \mathrm{~m}^{-2}$ because clouds with larger IWP are not discriminable in the CRISTA IWP retrieval. By this approach, zonal mean values of the model and the observation can be compared. A good correspondence is found in the zonal mean of IWP CRISTA and IWP CLAMS $_{\text {for }}$ altitudes at and below the tropopause, although the CLaMS values tend to be larger than CRISTA when penetrating to lower levels of the troposphere. The significant cloud occurrence rates of CRISTA and the vanishing probability of creating a cloud in the model become noticeable only above the tropopause, with means of IWP CRISTA $>$ IWP $_{\text {CLAMS }}$. The overall good correspondence below the tropopause indicates the dominance of optically thicker clouds below the tropopause, whereby the probability of both, model and observation, showing a similar size of the retrieved IWP values is much higher than for the much more variable optical thicknesses of cirrus clouds at and above the tropopause.

\subsection{LMS cloud formation in CLaMS}

To investigate the process of the formation of cirrus clouds in the lowermost stratosphere more closely, results from the CLaMS simulation and additional trajectory calculations are shown for regions where CRISTA observed clouds on $9 \mathrm{Au}-$ gust over Scandinavia. Since air masses in CLaMS loose their identity during mixing events, a bundle of backward trajectories was computed, starting at the locations of the ob- servations and ending 2 days earlier near positions where the last strong mixing occurred. These end points coincide with positions in the vicinity of the subtropical jet over the eastern United States (see Fig. 11). Longer backward trajectories are not only more difficult to identify with CLaMS air masses but, furthermore, end in areas with specific humidities too low to allow for the generation of cirrus clouds. This is due to the low temperatures the air masses experience on their way from the tropics into the mid- and higher latitudes.

This aspect emphasises the importance of mixing processes in the vicinity of the subtropical jet since this increases the water vapour content of the air masses under consideration sufficiently to enable cirrus formation. Longer backward trajectories (without mixing) result in air being too dry. From these positions ( 2 days earlier) cirrus forward simulations with $1 \mathrm{~h}$ time steps were started. The initialisation concerning water vapour and ice water content of the air masses was taken from the background atmosphere as simulated by the CLaMS model. The meteorological conditions concerning temperature and pressure were taken from ERA Interim data.

The results of the forward simulations are shown in Fig. 12 for all air masses that feature ice formation for the model case with conventional freeze-out at $100 \%$ saturation in the above-mentioned area. For a better visualisation of the life cycle of the simulated ice clouds, we show results from the start of the trajectories until 1 day after observation, i.e. 10 August. The temporal evolution of temperature and potential temperature along the trajectories (Fig. 12, top panel) show that, about 1 day before observation, the air masses underwent a cooling of about $10 \mathrm{~K}$ within roughly $6 \mathrm{~h}$, while still moving isentropically. This event coincides with an uplift of about $1 \mathrm{~km}$ over the North Atlantic caused by a dynamical low-pressure system cut off a trough located to the east (Fig. 12, centre panel).

Figure 12 (bottom panel) shows the formation of ice initiated by this cooling, setting on earlier for the model case with conventional freeze-out at $100 \%$ saturation than for the freeze-out at temperature-dependent supersaturation. Some air masses do not reach enough supersaturation for freezing to start. Those air masses that feature freezing for both model cases show similar amounts of gas phase water being converted to ice water. The ice clouds have lifetimes of between 14 and $26 \mathrm{~h}$ and are evaporated 1 day after observation. The vertical positions of the considered air masses are around $400 \mathrm{~m}$ above the tropopause (shown by the tropopause height along the trajectory computed from ERA Interim data in Fig. 12). The temporal evolution of the trajectories shows a model-consistent cross-tropopause transport around $12 \mathrm{~h}$ before the reference time (Fig. 12). At the reference time the air parcels correspond to the highest-altitude occurrences of ice water content with respect to the tropopause in the CLaMS model runs.

The results from the hemispheric CLaMS simulation (grey areas in Fig. 12, bottom panel) show smaller amounts of ice 

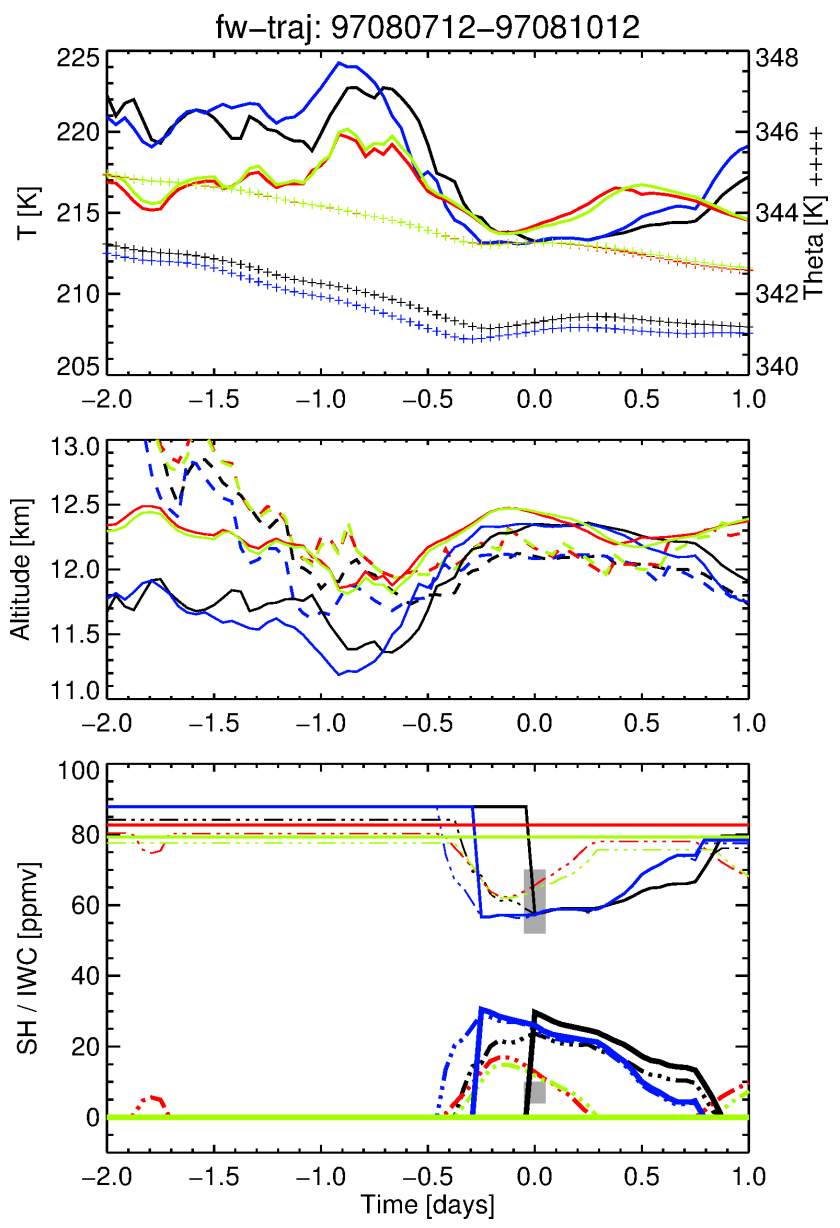

Figure 12. Forward trajectory calculations with respect to the reference time of 9 August at 12:00 UTC ( -2 days to +1 day) with $1 \mathrm{~h}$ temporal resolution and colour coded in the same way as the diamond symbols in Fig. 11 for the geographical location at reference time. Top: the panel shows temperature and potential temperature (crosses) versus time for the four trajectories shown in Fig. 11; middle: altitude (solid) and superimposed tropopause height (dashed line) based on ERA Interim at the location of the trajectory; bottom: specific humidity (thin lines) and ice water content (thick lines below $40 \mathrm{ppmv}$ ) as simulated with the CLaMS cirrus module. In addition, specific humidity (SH) and IWC for the conventional freezeout at $100 \%$ saturation (dash-dotted lines) are superimposed. Grey shaded areas indicate IWC and $\mathrm{SH}$ range in the original $24 \mathrm{~h}$ time step CLaMS model run at the reference time.

water content than the simulations done with pure trajectories and a higher temporal resolution at the time of the observation. This is due to the parameterisation used for the sedimentation of particles out of the model boxes. The CLaMS results already include the sedimentation of ice for a $24 \mathrm{~h}$ time step, while the results of the trajectory-based simulation maintain higher and slowly reducing ice water content during the day. Although this is merely an effect of time resolution, this may explain the fact that CRISTA observations show higher ice water content than CLaMS.
Sensitivity tests with the current set-up of CLaMS with changing saturation thresholds for ice formation (100 $150 \%)$ and varied radius parameterisations for the sedimentation process did not improve the comparison between the model and CRISTA in the LMS. Overall these variations in the set-up had little impact on the horizontal and vertical distribution of clouds in the LMS. In addition, temperature fluctuations by gravity waves causing high updraft velocities may play a key role in the nucleation process of ice particles (Spichtinger and Krämer, 2013). These temperature variations need to be considered accurately along the trajectory of an air parcel but are currently not available for the global modelling of cirrus clouds.

\section{Summary and conclusions}

A reanalysis of cloud and water vapour measurements during the CRISTA-2 mission in August 1997 in conjunction with model calculations with the Lagrangian chemical transport model CLaMS were presented. Special emphasis was placed on quantifying the cloud top altitude with respect to the local tropopause to demonstrate the potential importance of cirrus cloud formation in the lowermost stratosphere above the local tropopause. Little is known about the occurrence frequency and spatial distribution of this particular cloud phenomenon, for example, how and why these clouds may form. The occurrence of LMS clouds was previously reported by some lidar stations in the Northern Hemisphere, and occurrence frequencies above the tropopause of a few percent of the total number of cirrus profiles were reported. CRISTA observations extend these local observations to global coverage in the Northern Hemisphere and show strong indications for frequent cirrus occurrences in the LMS at mid- and high latitudes.

A reliable hemispheric picture of cloud occurrence in the LMS above the tropopause based on CRISTA-2 observations hinges on an accurate determination of the local tropopause. Here we applied a sophisticated new algorithm to the ERA Interim reanalysis data set. This so-called high-resolution tropopause was compared with TPHs from radiosonde data and showed a good agreement $( \pm 650 \mathrm{~m})$ for more than 5000 selected station profiles in the time frame of the CRISTA-2 mission. This demonstrates the good quality of the ERA Interim temperature profiles around the tropopause.

Uncertainties in the determination of the TPH location, instrument-specific effects such as the potential overestimation of the CTH for optically thick clouds due to the vertical extent of the field of view or uncertainties in the tangent height location were addressed in the present analysis. By quantifying all potential error sources as accurately as possible and modelling the effect of these uncertainties on cloud occurrence frequency statistics in tropopause related coordinates, the CRISTA observations show significant numbers 
of cirrus detections clearly above the local tropopause (500$1500 \mathrm{~m}$ ) and consequently in the lowermost stratosphere.

In general, the cloud top height occurrence frequencies (COF) in the midlatitude tropopause are in good agreement with the analysis of Pan and Mynchak (2011), based on the spaceborne lidar CALIOP, although these COFs are based on a multiannual seasonal mean. The CRISTA-2 results show larger COFs than CALIOP above the midlatitude tropopause $(>500 \mathrm{~m})$ and also above the tropical tropopause. Overall, rather high occurrence frequencies $(\sim 5-10 \%$ of all profiles) up to high northern latitudes $\left(70^{\circ} \mathrm{N}\right)$ and altitudes well above the tropopause $(>350 \mathrm{~K})$ were found in astonishingly large areas of the LMS. These numbers indicate a significantly larger occurrence frequency than in the ground-based observations.

Further, the Northern Hemisphere CRISTA water vapour observations indicate a considerable isentropic flux of moisture (at $\sim 350 \mathrm{~K}$ ) from the upper tropical troposphere into the extratropical LMS. This process is triggered by Rossby wave breaking events in the subtropical jet region accompanied by long-range transport of high water vapour abundance in streamer and filament structures from the subtropics to midand high latitudes. The process operates on timescales of few days, is observed at multiple geographical locations starting along the subtropical jet, and is in line with the temporal evolution of PV contours on the respective isentropic layers. Almost all LMS cirrus cloud observations are linked to areas of elongated contour lines of PV and water vapour and indicate an enhanced probability of observing LMS cirrus in the outflow and mixing regions associated with Rossby wave breaking events.

Comparisons of the CRISTA-2 measurements with results of CLaMS model simulations, where the model includes modules with parameterised cirrus processes, show a reasonable consistence for the horizontal distribution of cloud patterns in the tropopause region but differ in the vertical extent of the cloud fields and in the zonal mean occurrence frequency above the tropopause. Significantly fewer clouds are produced by the model well above the mid- and high-latitude tropopause than observed.

A limb ray tracing approach was applied through the 3-D model fields to obtain integrated measurement information through the atmosphere along the limb path of the instrument for a realistic and quantitative comparison of the model results and the measurements. The results confirm a connection between isentropic, quasi-horizontal transport of water vapour from the subtropics to the LMS in mid- and high latitudes and the occurrence of cirrus clouds in the lowermost stratosphere and tropopause region. However, the simplified cirrus scheme implemented in CLaMS seems to systematically underestimate the cloud occurrence frequencies in the LMS with respect to the observations.

Trajectory studies with the cirrus module of CLaMS in comparison with the CLaMS simulations show the importance of mixing for the formation of ice clouds in the LMS.
Mixing events at the subtropical jet can generate the entrance of enhanced vapour mixing ratios into the LMS, which favour the formation of ice clouds even at high latitudes over Scandinavia in the model in agreement with CRISTA observations.

Lidar observations of LMS cirrus above Jülich, Germany (Rolf, 2012), and single-cloud events in the CRISTA data set have been modelled along CLaMS trajectories (not shown) with a more sophisticated microphysical bulk model for ice formation (Spichtinger and Gierens, 2009a), and for the lidar observations also with a detailed aerosol microphysical model (MAID, Gensch et al., 2008). These preliminary tests could not reproduce the observed cloud structures, although additional temperature fluctuations were taken into account (personal communication C. Rolf and M. Krämer, 2014). Temperature fluctuations may play a key role in a realistic modelling of the formation process of cirrus (Spichtinger and Krämer, 2013) but are difficult to constrain, especially on global scales. Usually temperatures are not low enough and temperature variations are not fast enough to initiate ice formation under the model background conditions. Amongst other things, these first attempts of modelling the observations of LMS cirrus indicate that already the meteorological analyses used for the initialisation of water vapour, IWC, and the temperatures along the trajectories may not include the processes and variability (e.g. gravity waves or small-scale and high-frequency fluctuations) necessary to generate cirrus clouds in the LMS region. In addition, the formation processes of this specific cirrus cloud type may differ from the current knowledge and implementation in the current microphysical models.

Improvements and new developments in the cirrus modules in models as well as multi-instrumental analysis approaches are necessary to achieve progress concerning the questions and unknowns about the formation of cirrus clouds in the LMS. More accurate frequency distributions, seasonal cloud coverage of the Northern and Southern Hemisphere, and microphysical information regarding LMS cirrus are necessary to quantify the potential radiation and climate impact of LMS cirrus.

As a next step, optimised analyses of the currently bestsuited spaceborne and still-operating instrument for cloud studies, the CALIOP instrument on CALIPSO, would help to improve knowledge of cloud cover and frequency distribution on temporal and spatial scales. Spatial averaging of high-resolution CALIOP level 1 data has to be used to improve the detection sensitivity for optically very thin clouds. The unprecedentedly frequent and statistically significant observation of LMS cirrus by CRISTA may initiate more specific measurement campaigns or model studies with respect to LMS cirrus to quantify the importance of this still intriguing cloud type. 
Acknowledgements. The authors thank N. Thomas for her excellent programming support during the study. Radiosonde data were kindly provided by L. D. Oolman from the University of Wyoming. ERA Interim data used in this study have been provided by ECMWF. The authors would like to thank A. Dudhia, University of Oxford, for providing the radiative-transport model RFM; L. Pan, NCAR, for helpful comments on ideas on the tropopause determination based on reanalysis data sets; as well as M. Krämer, B. Vogel, C. Rolf, and F. Ploeger for discussions and comments during the work on the manuscript.

The service charges for this open access publication have been covered by a Research Centre of the Helmholtz Association.

Edited by: P. Haynes

\section{References}

Avery, M., Winker, D., Heymsfield, A., Vaughan, M., Young, S., $\mathrm{Hu}$, Y., and Trepte, C.: Cloud ice water content retrieved from the CALIOP space-based lidar, Geophys. Res. Lett., 19, L05808, doi:10.1029/2011GL050545, 2012.

Birner, T.: Fine scale structure of the extratropical tropopause region, J. Geophys. Res., 111, D04104, doi:10.1029/2005JD006301, 2006.

Bodas-Salcedo, A., Webb, M. J., Bony, S., Chepfer, H., Dufresne, J.-L., Klein, S. A., Zhang, Y., Marchand, R., Haynes, J. M., Pincus, R., and John, V. O.: COSP: satellite simulation software for model assessment, B. Am. Meteorol. Soc., 92, 1023-1043, doi:10.1175/2011BAMS2856.1, 2011.

Chepfer, H., Bony, S., Winker, D., Cesana, G., Dufresne, J. L., Minnis, P., Stubenrauch, C. J., and Zeng, S.: The GCM Oriented CALIPSO Cloud Product (CALIPSO-GOCCP), J. Geophys. Res., 115, D00H16, doi:10.1029/2009JD012251, 2010.

Davis, S., Hlavka, D., Jensen, E., Rosenlof, K., Yang, Q., Schmidt, S., Borrmann, S., Frey, W., Lawson, P., Voemel, H., and Bui, T. P.: In situ and lidar observations of subvisible cirrus clouds during TC4, J. Geophys. Res., 115, D00J17, doi:10.1029/2009JD013093, 2010.

Dee, D. P., Uppala, S. M., Simmons, A. J., Berrisford, P., Poli, P., Kobayashi, S., Andrae, U., Balmaseda, M. A., Balsamo, G., Bauer, P., Bechtold, P., Beljaars, A. C. M., van de Berg, L., Bidlot, J., Bormann, N., Delsol, C., Dragani, R., Fuentes, M., Geer, A. J., Haimberger, L., Healy, S. B., Hersbach, H., Holm, E. V., Isaksen, L., Kallberg, P., Koehler, M., Matricardi, M., McNally, A. P., Monge-Sanz, B. M., Morcrette, J. J., Park, B. K., Peubey, C., de Rosnay, P., Tavolato, C., Thepaut, J. N., and Vitart, F.: The ERA-Interim reanalysis: configuration and performance of the data assimilation system, Q. J. Roy. Meteor. Soc., 137, 553-597, doi:10.1002/qj.828, 2011.

Deshler, T., Hervig, M. E., Hofmann, D. J., Rosen, J. M., and Liley, J. B.: Thirty years of in situ stratospheric aerosol size distribution measurements from Laramie, Wyoming $\left(41^{\circ} \mathrm{N}\right)$, using balloon-borne instruments, J. Geophys. Res., 108, 4167, doi:10.1029/2002JD002514, 2003.
Dessler, A. E.: Clouds and water vapor in the Northern Hemisphere summertime stratosphere, J. Geophys. Res., 114, D00H09, doi:10.1029/2009JD012075, 2009.

Dionisi, D., Keckhut, P., Liberti, G. L., Cardillo, F., and Congeduti, F.: Midlatitude cirrus classification at Rome Tor Vergata through a multichannel Raman-Mie-Rayleigh lidar, Atmos. Chem. Phys., 13, 11853-11868, doi:10.5194/acp-13-118532013, 2013.

Dudhia, A., Morris, P. E., and Wells, R. J.: Fast monochromatic radiative transfer calculations for limb sounding, J. Quant. Spectrosc. Ra., 74, 745-756, 2002.

Dupont, J.-C., Haeffelin, M., Morille, Y., Noel, V., Keckhut, P., Winker, D., Comstock, J., Chervet, P., and Roblin, A.: Macrophysical and optical properties of midlatitude cirrus clouds from four ground-based lidars and collocated CALIOP observations, J. Geophys. Res., 115, D00H24, doi:10.1029/2009JD011943, 2010.

Eixmann, R., Peters, D., Zülicke, Ch., Gerding, M., and Dörnbrack, A.: On the upper tropospheric formation and occurence of high and thin cirrus clouds during anticyclonic poleward Rossby wave breaking events, Tellus A, 62, 228-242, doi:10.1111/j.1600-0870.2010.00437.x, 2010.

Fischer, H., Birk, M., Blom, C., Carli, B., Carlotti, M., von Clarmann, T., Delbouille, L., Dudhia, A., Ehhalt, D., Endemann, M., Flaud, J. M., Gessner, R., Kleinert, A., Koopman, R., Langen, J., López-Puertas, M., Mosner, P., Nett, H., Oelhaf, H., Perron, G., Remedios, J., Ridolfi, M., Stiller, G., and Zander, R.: MIPAS: an instrument for atmospheric and climate research, Atmos. Chem. Phys., 8, 2151-2188, doi:10.5194/acp-8-2151-2008, 2008.

Fromm, M., Lindsey, D.T., Servranckx, R., Yue, G., Trickl, T., Sica, R., Doucet, P., and Godin-Beekmann, S.: The Untold Story of Pyrocumulonimbus. Bull. Amer. Meteor. Soc., 91, 1193-1209. doi:10.1175/2010BAMS3004.1, 2010.

Fueglistaler, S., Dessler, A. E., Dunkerton, T. J., Folkins, I., Fu, Q., and Mote, P. W.: Tropical tropopause layer, Rev. Geophys., 47, RG1004, doi:10.1029/2008RG000267, 2009.

Fusina, F., Spichtinger, P., and Lohmann, U.: The impact of ice supersaturated regions and thin cirrus on radiation in the mid-latitudes, J. Geophy. Res., 112, D24S14, doi:10.1029/2007JD008449, 2007.

Gabriel, A. and Peters, D.: A diagnostic study of different types of Rossby wave breaking events in the northern extra-tropics, J. Meteorol. Soc. Jpn., 86, 613-631, 2008.

Gensch, I., Bunz, H., Baumgardner, D.,Christensen, L. E., Fahey, D. W., Hermann, R. L., Lawson, P., Popp, P., Smith, J. B., Webster, C. R., Weinstock, E. M., Wilson, J. C., Peter, T., Krämer, M.: Supersaturations, microphysics and nitric acid partitioning in a cold cirrus observed during CR-AVE 2006: an observation-modeling intercomparison study, Environ. Res. Lett., 3, 035003, doi:10.1088/1748-9326/3/3/035003, 2008.

Griessbach, S., Hoffmann, L., Spang, R., and Riese, M.: Volcanic ash detection with infrared limb sounding: MIPAS observations and radiative transfer simulations, Atmos. Meas. Tech., 7, 14871507, doi:10.5194/amt-7-1487-2014, 2014.

Griessbach, S., Hoffmann, L., Spang, R., von Hobe, M., Müller, R., and Riese, M.: MIPAS Volcanic Sulfate Aerosol Observations of the Nabro Eruption, in: Stratospheric Sulfur and its Role in Climate (SSiRC), Atlanta, Georgia, USA, October 2013, SPARC, 
available at: http://www.sparc-ssirc.org/downloads/Griessbach. pdf, 2013.

Gettelman, A., Hoor, P., Pan, L. L., Randel, W. J., Hegglin, M. I., and Birner, T.: The extratropical upper troposphere and lower stratosphere, Rev. Geophys., 49, RG3003, doi:10.1029/2011RG000355, 2011.

Gierens, K., Schumann, U., Helten, M., Smit, H. and Wang, P.-H.: Ice-supersaturated regions and subvisible cirrus in the northern midlatitudes upper troposphere, J. Geophys. Res., 105, 2274322753, 2000.

Grossmann, K. U., Offermann, D., Gusev, O., Oberheide, J., Riese, M., and Spang, R.: The CRISTA-2 mission, J. Geophys. Res., 107, 8173, doi:10.1029/2001JD000667, 2002.

Hegglin, M. I., Boone, C. D., Manney, G. L., and Walker, K. A.: A global view of the extratropical tropopause transition layer from Atmospheric Chemistry Experiment Fourier Transform Spectrometer $\mathrm{O}_{3}, \mathrm{H}_{2} \mathrm{O}$, and CO, J. Geophys. Res., 114, D00B11, doi:10.1029/2008JD009984, 2009.

Hoffmann, L. and Alexander, M. J.: Occurrence frequency of convective gravity waves during the North American thunderstorm season, J. Geophys. Res., 115, D20111, doi:10.1029/2010JD014401, 2010.

Holton, J. R., Haynes, P. H., McIntyre, M. E., Douglass, A. R., Rood, R. B., and Pfister, L.: Stratosphere-troposphere exchange, Rev. Geophys., 33, 403-439, doi:10.1029/95RG02097, 1995.

Homeyer, C. R. and Bowman, K. P.: Rossby wave breaking and transport between the tropics and extratropics above the subtropical jet, J. Atmos. Sci., 70, 607-626, doi:10.1175/JAS-D-120198.1, 2013.

Hoor, P., Wernli, H., Hegglin, M. I., and Bönisch, H.: Transport timescales and tracer properties in the extratropical UTLS, Atmos. Chem. Phys., 10, 7929-7944, doi:10.5194/acp-10-79292010, 2010.

Höpfner, M., Pitts, M. C., and Poole L. R.: Comparison between CALIPSO and MIPAS observations of polar stratospheric clouds, J. Geophys. Res., 114, D00H05, doi:10.1029/2009JD012114. 2009.

Hoareau, C., Keckhut, P., Noel, V., Chepfer, H., and Baray, J.L.: A decadal cirrus clouds climatology from ground-based and spaceborne lidars above the south of France $\left(43.9^{\circ} \mathrm{N}-5.7^{\circ} \mathrm{E}\right)$, Atmos. Chem. Phys., 13, 6951-6963, doi:10.5194/acp-13-69512013, 2013.

IPCC: Climate Change 2013 - The Physical Science Basis, Working Group I Contribution to the Fifth Assessment Report of the Intergovernmental Panel on Climate Change, edited by: Intergovernmental Panel on Climate Change, Cambridge University Press, Cambridge, UK and New York, NY, USA, 2014.

Jones, R. L. and Pyle, J. A.: Observations of $\mathrm{CH}_{4}$ and $\mathrm{N}_{2} \mathrm{O}$ by the NIMBUS 7 SAMS: a comparison with in situ data and two dimensional numerical model calculations, J. Geophys. Res., 89, 5263-5279, 1984.

Juckes, M. N. and McIntyre, M. E.: A high-resolution one-layer model of breaking planetary waves in the stratosphere, Nature, 328, 590-596, 1987.

Kärcher, B. and Spichtinger, P.: Cloud-controlling factors of cirrus, in: Clouds in the Perturbed Climate System: Their Relationship to Energy Balance, Atmospheric Dynamics, and Precipitation, Strüngmann Forum Report, volume 2, edited by: Heintzenberg, J. and Charlson, R. J., MIT Press, Cambridge, MA, 2009.
Keckhut, P., Hauchecorne, A., Bekki, S., Colette, A., David, C., and Jumelet, J.: Indications of thin cirrus clouds in the stratosphere at mid-latitudes, Atmos. Chem. Phys., 5, 3407-3414, doi:10.5194/acp-5-3407-2005, 2005.

Kent, G. S., Winker, D. M., Vaughan, M. A., Wang, P.H., and Skeens, K. M.: Simulation of Stratospheric Aerosol and Gas Experiment (SAGE) II cloud measurements using airborne lidar data, J. Geophys. Res., 102, 21795-21807, doi:10.1029/97JD01390, 1997.

Konopka, P., Günther, G., Müller, R., dos Santos, F. H. S., Schiller, C., Ravegnani, F., Ulanovsky, A., Schlager, H., Volk, C. M., Viciani, S., Pan, L. L., McKenna, D.-S., and Riese, M.: Contribution of mixing to upward transport across the tropical tropopause layer (TTL), Atmos. Chem. Phys., 7, 32853308, doi:10.5194/acp-7-3285-2007, 2007.

Koop, T., Luo, B. P., Tsias, A., and Peter, T.: Water activity as the determinant for homogeneous ice nucleation in aqueous solutions, Nature, 406, 611-614, 2000.

Krämer, M., Schiller, C., Afchine, A., Bauer, R., Gensch, I., Mangold, A., Schlicht, S., Spelten, N., Sitnikov, N., Borrmann, S., de Reus, M., and Spichtinger, P.: Ice supersaturations and cirrus cloud crystal numbers, Atmos. Chem. Phys., 9, 3505-3522, doi:10.5194/acp-9-3505-2009, 2009.

Kunz, A., Müller, R., Homonnai, V., Jánosi, I. M., Hurst, D., Rap, A., Forster, P. M., Rohrer, F., Spelten, N., and M. Riese, M.: Extending water vapor trend observations over Boulder into the tropopause region: trend uncertainties and resulting radiative forcing, J. Geophys. Res.-Atmos., 118, 11269-11284, doi:10.1002/jgrd.50831, 2013.

Lamquin, N., Stubenrauch, C. J., Gierens, K., Burkhardt, U., and Smit, H.: A global climatology of upper-tropospheric ice supersaturation occurrence inferred from the Atmospheric Infrared Sounder calibrated by MOZAIC, Atmos. Chem. Phys., 12, 381405, doi:10.5194/acp-12-381-2012, 2012.

Luo, B. P., Peter, Th., Wernli, H., Fueglistaler, S., Wirth, M., Kiemle, C., Flentje, H., Yushkov, V. A., Khattatov, V., Rudakov, V., Thomas, A., Borrmann, S., Toci, G., Mazzinghi, P., Beuermann, J., Schiller, C., Cairo, F., Di Don-Francesco, G., Adriani, A., Volk, C. M., Strom, J., Noone, K., Mitev, V., MacKenzie, R. A., Carslaw, K. S., Trautmann, T., Santacesaria, V., and Stefanutti, L.: Ultrathin Tropical Tropopause Clouds (UTTCs): II. Stabilization mechanisms, Atmos. Chem. Phys., 3, 1093-1100, doi:10.5194/acp-3-1093-2003, 2003.

Massie, S., Gille, J., Khosravi, R., Lee, H., Kinnison, D., Francis, G., Nardi, B., Eden, T., Craig, C., Halvorson, C., Coffey, M., Packman, D., Cavanaugh, C., Craft, J., Dean, V., Ellis, D., Barnett, J., Hepplewhite, C., Lambert, A., Manney, G., Strawa, A., and Legg, M.: High Resolution Dynamics Limb Sounder observations of polar stratospheric clouds and subvisible cirrus, J. Geophys. Res., 112, D24S31, doi:10.1029/2007JD008788, 2007.

Mahowald, N. M., Plumb, R. A., Rasch, P. J., del Corral, J., and Sassi, F.: Stratospheric transport in a three-dimensional isentropic coordinate model, J. Geophys. Res., 107, 4254, doi:10.1029/2001JD001313, 2002.

McKenna, D. S., Konopka, P., Grooß, J.-U., Günther, G., Müller, R., Spang, R., Offermann, D., and Orsolini, Y.: A new Chemical Lagrangian Model of the Stratosphere (CLaMS): 1. Formulation of advection and mixing, J. Geophys. Res., 107, 4309, doi:10.1029/2000JD000114, 2002a. 
McKenna, D. S., Grooß, J.-U., Günther, G., Konopka, P., Müller, R., Carver, G., and Sasano, Y.: A new Chemical Lagrangian Model of the Stratosphere (CLaMS): 2. Formulation of chemistry scheme and initialization, J. Geophys. Res., 107, 4256, doi:10.1029/2000JD000113, 2002b.

Mergenthaler, J., Roche, A. E., Kumer, J. B., and Ely, G.: Cryogenic Limb Array Etalon Spectrometer observations of tropical cirrus, J. Geophys. Res., 104, 22183-22194, doi:10.1029/1999JD900397, 1999.

Mitchell, D. L. and Finnegan, W.: Modification of cirrus clouds to reduce global warming, Environ. Res. Lett., 4, 045102, doi:10.1088/1748-9326/4/4/045102, 2009.

Mitchell, D. L., Rasch, P., Ivanova, D., McFarquhar, G., and Nousiainen, T.: Impact of small ice crystal assumptions on ice sedimentation rates in cirrus clouds and GCM simulations, Geophys. Res. Lett., 35, L09806, doi:10.1029/2008GL033552, 2008.

Montoux, N., Keckhut, P., Hauchecorne, A., Jumelet, J., Brogniez, H., and David, C.: Isentropic modeling of a cirrus cloud event observed in the midlatitude upper troposphere and lower stratosphere, J. Geophys. Res., 115, D02202, doi:10.1029/2009JD011981, 2010.

Noel, V. and Haeffelin, M.: Midlatitude cirrus clouds and multiple tropopauses from a 2002-2006 climatology over the SIRTA observatory, J. Geophys. Res., 112, D13206, doi:10.1029/2006JD007753, 2007.

Offermann, D., Grossmann, K. U., Barthol, P., Knieling, P., Riese, M., and Trant, R.: The CRyogenic Infrared Spectrometers and Telescopes for the Atmosphere (CRISTA) experiment and middle atmosphere variability, J. Geophys. Res., 104, 16311$16325,1999$.

Offermann, D., Schaeler, B., Riese, M., Langfermann, M., Jarisch, M., Eidmann, G., Schiller, C., Smit, H. G. J., and Read, W. G.: Water vapor at the tropopause during the CRISTA 2 mission, J. Geophys. Res., 107, 8176, doi:10.1029/2001JD000700, 2002.

Pan, L. L. and Munchak, L. A.: Relationship of cloud top to the tropopause and jet structure from CALIPSO data, J. Geophys. Res., 116, D12201, doi:10.1029/2010JD015462, 2011.

Pan, L. L., Randel, W. J., Gary, B. L., Mahoney, M. J., and Hintsa, E. J.: Definitions and sharpness of the extratropical tropopause: a trace gas perspective, J. Geophys. Res., 109, D23103, doi:10.1029/2004JD004982, 2004.

Pan, L. L., Bowman, K. P., Shapiro, M., Randal, W. J., Gao, R. S., Campos, T., Davis, C., Schauer, S., Ridley, B. A., Wei, J. C., and Barnet, C.: Chemical behavior of the tropopause observed during the Stratosphere-Troposphere Analyses of Regional Transport experiment, J. Geophys. Res., 112, D18110, doi:10.1029/2007JD008645, 2007.

Peter, Th., Luo, B. P., Wirth, M., Kiemle, C., Flentje, H., Yushkov, V. A., Khattatov, V., Rudakov, V., Thomas, A., Borrmann, S., Toci, G., Mazzinghi, P., Beuermann, J., Schiller, C., Cairo, F., Di Donfrancesco, G., Adriani, A., Volk, C. M., Strom, J., Noone, K., Mitev, V., MacKenzie, R. A., Carslaw, K. S., Trautmann, T., Santacesaria, V., and Stefanutti, L.: Ultrathin Tropical Tropopause Clouds (UTTCs): I. Cloud morphology and occurrence, Atmos. Chem. Phys., 3, 1083-1091, doi:10.5194/acp-3-1083-2003, 2003.

Ploeger, F., Fueglistaler, S., Grooß, J.-U., Günther, G., Konopka, P., Liu, Y. S., Müller, R., Ravegnani, F., Schiller, C., Ulanovski, A., and Riese, M.: Insight from ozone and water vapour on transport in the tropical tropopause layer (TTL), Atmos. Chem. Phys., 11, 407-419, doi:10.5194/acp-11-407-2011, 2011.

Ploeger, F., Günther, G., Konopka, P., Fueglistaler, S., Müller, R., Hoppe, C., Kunz, A., Spang, R., Grooß, J.-U., and Riese, M.: Horizontal water vapor transport in the lower stratosphere from subtropics to high latitudes during boreal summer, J. Geophys. Res.-Atmos., 118, 8111-8127, doi:10.1002/jgrd.50636, 2013.

Postel, G. A. and Hitchman, M. H.: A climatology of rossby wave breaking along the subtropical tropopause, J. Atmos. Sci., 56, 359-373, doi:10.1175/15200469(1999)056<0359:ACORWB>2.0.CO;2, 1999.

Riese, M., Tie, X., Brasseur, G., and Offermann, D.: Threedimensional simulation of stratospheric trace gas distributions measured by CRISTA, J. Geophys. Res., 104, 16419-16435, doi:10.1029/1999JD900178, 1999a.

Riese, M., Spang, R., Preusse, P., Ern, M., Jarisch, M., Offermann, D., and Grossmann, K. U.: Cryogenic Infrared Spectrometers and Telescopes for the Atmosphere (CRISTA) data processing and atmospheric temperature and trace gas retrieval, J. Geophys. Res., 104, 16349-16367, doi:10.1029/1998JD100057, 1999b.

Riese, M., Manney, G. L., Oberheide, J., Tie, X., Spang, R., and Kull, V.: Stratospheric transport by planetary wave mixing as observed during CRISTA-2, J. Geophys. Res., 107, 8179, doi:10.1029/2001JD000629, 2002.

Riese, M., Ploeger, F., Rap, A., Vogel, B., Konopka, P., Dameris, M., and Forster, P.: Impact of uncertainties in atmospheric mixing on simulated UTLS composition and related radiative eects, J. Geophys. Res., 117, D16305, doi:10.1029/2012JD017751, 2012.

Rohs, S., Schiller, C., Riese, M., Engel, A., Schmidt, U., Wetter, T., Levin, I., Nakazawa, T., and Aoki, S.: Long-term changes of methane and hydrogen in the stratosphere in the period 19782003 and their impact on the abundance of stratospheric water vapor, J. Geophys. Res., 111, 1-12, doi:10.1029/2005JD006877, 2006.

Rolf, C.: Lidar Observations of Natural and Volcanic-ash-induced Cirrus Clouds, Schriften des Forschungszentrum Jülich, Reihe Energie \& Umwelt, Band 163, Jülich, 2013.

Sanderson, B. M., Piani, C., Ingram, W. J., Stone, D. A., and Allen, M. R.: Towards constraining climate sensitivity by linear analysis of feedback patterns in thousands of perturbed-physics GCM simulations, Clim. Dynam., 30, 175-190, 2008.

Sassen, K., Griffin, M. K., and Dodd, G. C.: Optical scattering and microphysical properties of subvisible cirrus clouds, and climatic implications, J. Appl. Meteorol., 28, 91-98, 1989.

Schaeler, B. and Riese, M.: Retrieval of water vapor in the tropopause region from CRISTA measurements, Adv. Space Res., 27, 1635-1640, doi:10.1016/S0273-1177(01)002289, 2001.

Schaeler, B., Offermann, D., Kuell, V., Jarisch, M., Feldmann, H., and Ebel, A.: Regional and global trace gas distributions and inferred transports in the upper troposphere and lower stratosphere, J. Geophys. Res., 110, D09104, doi:10.1029/2004JD004994, 2005.

Sembhi, H., Remedios, J., Trent, T., Moore, D. P., Spang, R., Massie, S., and Vernier, J.-P.: MIPAS detection of cloud and aerosol particle occurrence in the UTLS with comparison to 
HIRDLS and CALIOP, Atmos. Meas. Tech., 5, 2537-2553, doi:10.5194/amt-5-2537-2012, 2012.

Solomon, S., Rosenlof, K., Portmann, R., Daniel, J., Davis, S., Sanford, T., and Plattner, G.-K.: Contributions of stratospheric water vapor to decadal changes in the rate of global warming, Science, 327, 1219-1223, doi:10.1126/science.1182488, 2010.

Spang, R. and Remedios, J.: Observations of a distinctive infrared spectral feature in the atmospheric spectra of polar stratospheric clouds measured by the CRISTA instrument, Geophys. Res. Lett., 30, 1875, doi:10.1029/2003GL017231, 2003.

Spang, R., Riese, M., and Offermann, D.: CRISTA-2 observations of the south polar vortex in winter 1997: a new data set for polar process studies, Geophys. Res. Lett., 28, 3159-3162, 2001.

Spang, R., Eidmann, G., Riese, M., Offermann, D., Preusse, P., Pfister, L., and Wang, P. H.: CRISTA observations of cirrus clouds around the tropopause, J. Geophys. Res., 107, 8174, doi:10.1029/2001JD000698, 2002.

Spang, R., Remedios, J. J., and Barkley, M.: Colour indices for the detection and differentiation of cloud types in infra-red limb emission spectra, Adv. Space Res., 33, 1041-1047, 2004.

Spang, R., Remedios, J. J., Kramer, L. J., Poole, L. R., Fromm, M. D., Müller, M., Baumgarten, G., and Konopka, P.: Polar stratospheric cloud observations by MIPAS on ENVISAT: detection method, validation and analysis of the northern hemisphere winter 2002/2003, Atmos. Chem. Phys., 5, 679-692, doi:10.5194/acp-5-679-2005, 2005a.

Spang, R., Remedios, J. J., Tilmes, S., and Riese, M.: MIPAS observation of polar stratospheric clouds in the Arctic 2002/2003 and Antarctic 2003 winters, Adv. Space Res., 36, 868-878, 2005 b.

Spang, R., Hoffmann, L., Kullmann, A., Olschewski, F., Preusse, P., Knieling, P., Schroeder, S., Stroh, F., Weigel, K., and Riese, M.: High resolution limb observations of clouds by the CRISTA-NF experiment during the SCOUT-O3 Tropical Aircraft campaign, Adv. Space Res., 42, 1765-1775, 2007.

Spang, R., Arndt, K., Dudhia, A., Höpfner, M., Hoffmann, L., Hurley, J., Grainger, R. G., Griessbach, S., Poulsen, C., Remedios, J. J., Riese, M., Sembhi, H., Siddans, R., Waterfall, A., and Zehner, C.: Fast cloud parameter retrievals of MIPAS/Envisat, Atmos. Chem. Phys., 12, 7135-7164, doi:10.5194/acp-12-71352012, 2012.

SPARC: Assessment of Stratospheric Aerosol Properties (ASAP), edited by: Thomason, L. W. and Peter, T., SPARC Report No. 4, WCRP-124, WMO/TD, No. 1295, http://www.sparc-climate. org/publications/sparc-reports/sparc-report-no4/, 2006.

Spichtinger, P., Gierens, K., Leiterer, U., and Dier, H.: Ice supersaturation in the tropopause region over Lindenberg, Germany, Meteorol. Z., 12, 143-156, 2003a.

Spichtinger, P., Gierens, K., and Read, W.: The global distribution of ice-supersaturated regions as seen by the Microwave Limb Sounder, Quat. J. Roy. Meteor. Soc., 129, 3391-3410, 2003 b.

Spichtinger, P. and Gierens, K. M.: Modelling of cirrus clouds Part 1a: Model description and validation, Atmos. Chem. Phys., 9, 685-706, doi:10.5194/acp-9-685-2009, 2009a.

Spichtinger, P. and Gierens, K. M.: Modelling of cirrus clouds - Part 1b: Structuring cirrus clouds by dynamics, Atmos. Chem. Phys., 9, 707-719, doi:10.5194/acp-9-707-2009, 2009b.
Spichtinger, P. and Krämer, M.: Tropical tropopause ice clouds: a dynamic approach to the mystery of low crystal numbers, Atmos. Chem. Phys., 13, 9801-9818, doi:10.5194/acp-13-98012013, 2013.

Tuck, A. F., Baumgardner, D., Chan, K. R., Dye, J. E., Elkins, J. W., Hovde, S. J., Kelly, K. K., Loewenstein, M., Margitan, J. J., May, R. D., Podolske, J. R., Prott, M. H., Rosenlof, K. H., Smith, W. L., Webster, C. R., and Wilson, J. C.: The Brewer-Dobson circulation in the light of high altitude in situ aircraft observations, Q. J. Roy. Meteor. Soc., 123, 1-69, doi:10.1002/qj.49712353702, 1997.

von Hobe, M., Grooß, J.-U., Günther, G., Konopka, P., Gensch, I., Krämer, M., Spelten, N., Afchine, A., Schiller, C., Ulanovsky, A., Sitnikov, N., Shur, G., Yushkov, V., Ravegnani, F., Cairo, F., Roiger, A., Voigt, C., Schlager, H., Weigel, R., Frey, W., Borrmann, S., Müller, R., and Stroh, F.: Evidence for heterogeneous chlorine activation in the tropical UTLS, Atmos. Chem. Phys., 11, 241-256, doi:10.5194/acp-11-241-2011, 2011.

Vernier, J.-P., Thomason, L. W., and Kar, J.: CALIPSO detection of an Asian tropopause aerosol layer, Geophys. Res. Lett., 38, L07804, doi:10.1029/2010GL046614, 2011.

Wang, P. H., Minnis, P., McCormick, M. P., Kent, G. S., and Skeens, K. S., A 6-year climatology of cloud occurrence frequency from SAGE II observations (1985-1990), J. Geophys. Res., 101, 29407-29429, 1996.

Wang, T. and Dessler, A. E.: Analysis of cirrus in the tropical tropopause layer from CALIPSO and MLS data: a water perspective, J. Geophys. Res., 117, D04211, doi:10.1029/2011JD016442, 2012.

Wattenbach, R. and Moritz, K.: Astronomical shuttle pallet satellite (ASTRO-SPAS), Acta Astronaut., 40, 723-732, 1997.

Wendisch, M., Yang, P., and Pilewskie, P.: Effects of ice crystal habit on thermal infrared radiative properties and forcing of cirrus, J. Geophys. Res., 112, D08201, doi:10.1029/2006JD007899, 2008.

Winker, D. M., Vaughan, M. A., Omar, A. H., Hu, Y., Powell, K. A., Liu, Z., Hunt, W. H., and Young, S. A.: Overview of the CALIPSO Mission and CALIOP Data Processing Algorithms, J. Atmos. Ocean. Tech., 26, 2310-2323, doi:10.1175/2009JTECHA1281.1, 2009.

Wooster, M. J., Perry, G. L. W., and Zoumas, A.: Fire, drought and El Niño relationships on Borneo (Southeast Asia) in the pre-MODIS era (1980-2000), Biogeosciences, 9, 317-340, doi:10.5194/bg-9-317-2012, 2012.

World Meteorological Organization (WMO): Meteorology a Threedimensional Science: Second Session of the Commission for Aerology, WMO Bulletin IV(4), WMO, Geneva, 134-138, 1957.

Zhang, M. H., Lin, W. Y., Klein, S. A., Bacmeister, J., Bony, S., Cederwall, R. T., Del Genio, A., Hack, J. J., Loeb, N., Lohmann, U., Minnis, P., Musat, I., Pincus, R., Stier, P., Suarez, M. J. Webb, J., Xie, S. C., Yao, M., and Zhang, J. H.: Comparing clouds and their seasonal variations in atmospheric general circulation models with satellite measurements, J. Geophys. Res., 110, D15S02, doi:10.1029/2004JD005021, 2005. 